'Department of Obstetrics \& Gynecology, Wayne State University School of Medicine, Detroit, MI, USA.

${ }^{2}$ Department of Health Systems and Sciences Research and Department of Epidemiology and Biostatistics, Drexel University, Philadelphia, $P A$, USA.

${ }^{3}$ Department of Epidemiology and Biostatistics, College of Human Medicine, Michigan State University, East Lansing, MI, USA.

4Michigan Department of Health and Human Services, Lansing, MI, USA.

${ }^{5}$ Department of Pediatrics and Human Development, College of Human Medicine, Michigan State University. East Lansing, MI, USA.

*e-mail:sKorzeni@

med.wayne.edu

https://doi.org/10.1038, s41582-018-0043-6

\title{
The complex aetiology of cerebral palsy
}

\author{
Steven J. Korzeniewski ${ }^{*}$, Jaime Slaughter ${ }^{2}$, Madeleine Lenski ${ }^{3}$, Peterson Haak ${ }^{4}$ and \\ Nigel Paneth ${ }^{3,5}$
}

Abstract | Cerebral palsy (CP) is the most prevalent, severe and costly motor disability of childhood. Consequently, CP is a public health priority for prevention, but its aetiology has proved complex. In this Review, we summarize the evidence for a decline in the birth prevalence of $\mathrm{CP}$ in some high-income nations, describe the epidemiological evidence for risk factors, such as preterm delivery and fetal growth restriction, genetics, pregnancy infection and other exposures, and discuss the success achieved so far in prevention through the use of magnesium sulfate in preterm labour and therapeutic hypothermia for birth-asphyxiated infants. We also consider the complexities of disentangling prenatal and perinatal influences, and of establishing subtypes of the disorder, with a view to accelerating the translation of evidence into the development of strategies for the prevention of CP.

Cerebral palsy $(\mathrm{CP})$ is the most common severe motor disability in children, and its severity is demonstrated by the fact that $40 \%$ of children with the condition cannot walk independently ${ }^{1,2}$, one-third have epilepsy ${ }^{3}$, up to one-third are non-verbal ${ }^{4,5}$ and about one-half have some degree of cognitive impairment ${ }^{2,6-8}$. Lifetime costs for a child with CP in the USA have been estimated at just under US\$1 million per individual for health expenditures, educational needs, social services and lost economic opportunity 9 . The prevalence, severity and burden of CP make it a public health priority for prevention, and recognition that perinatal exposures and pregnancy complications are strongly linked to the risk of CP provides opportunities for prevention. However, the aetiology of $\mathrm{CP}$ has proved complex, making progress in its prevention difficult.

In this Review, we consider the epidemiological observations that provide evidence for the contribution of various developmental pathways to the pathogenesis of $\mathrm{CP}$ and for the substantial success in prevention to date. We also consider the complexities of disentangling prenatal and perinatal influences, with a view to accelerating the translation of evidence into clinical approaches to the prevention of CP.

\section{The prevalence of cerebral palsy}

In the 1940s, in the USA, two voluntary organizations, the National Society for Crippled Children (later named Easter Seals) and United Cerebral Palsy, initiated two population surveys to determine CP prevalence ${ }^{10,11}$. In Schenectady, New York, the prevalence was 5.9 cases per 1,000 births, whereas in Minneapolis, Minnesota, the prevalence was 1.8 per 1,000 live births ${ }^{10,11}$. These differences in prevalence indicated that defining $\mathrm{CP}$, differentiating $\mathrm{CP}$ from other motor disabilities and determining the precise lower limits of severity that delineate cases were all problematic. This difficulty has been repeatedly wrestled with, and numerous international meetings on the definition and classification of CP have been held since 1958 (REFS ${ }^{12-14}$ ), each leading to changes in the definition of the condition (FIG. 1).

Ongoing population surveillance for $\mathrm{CP}$ began in the Nordic countries ${ }^{15-17}$. In the second half of the past century, most reviews concluded that the prevalence of $\mathrm{CP}$ (generally expressed in relation to numbers of live births) in industrialized nations was fairly stable at $1.5-2.5$ cases per 1,000 live births ${ }^{18,19}$, but with a modest increase in the last two decades of the 20th century owing largely to the greatly increased survival of very premature infants as a result of the success of the new technology ${ }^{19,20}$.

Estimates of CP prevalence in the 21st century, however, reveal a mixed picture. During the first decade of the century, estimates of $\mathrm{CP}$ prevalence were generally higher than in the 20th century in high-income countries (HICs). In the USA, prevalence estimates increased from 2 to as high as 3 cases per 1,000 live births between 2002 and $2012\left(\mathrm{REFS}^{2,21-25}\right.$ ), although the most recent of these surveys showed a slight decline to 2.9 per 1,000 8 -year-old children in 2010 from 3.5 in the same surveillance area in 2006 (REF. ${ }^{26}$ ). However, studies in Australia $^{3}$, Europe ${ }^{27-29}$, Canada $^{30}$, Sweden $^{31}$ and Japan ${ }^{32}$ have provided evidence for a declining prevalence of $\mathrm{CP}$ over time, mostly among low-birthweight and preterm infants (TABLE 1). In China, a decline from 1.6 to 


\section{Key points}

- Several high-income countries have reported a decline in the prevalence of cerebral palsy (CP); therapeutic hypothermia and magnesium sulfate for neuroprotection might have played a role, but other factors might be important.

- The minimum age at which CP can be reliably diagnosed is controversial; evidence that early diagnosis and intervention improves motor outcome is sparse, but there are hints of benefits for cognitive outcomes.

- No consensus exists about CP subtypes; the general term CP is important for public health and health services planning, but subtypes might have different aetiologies.

- Gestational age and birthweight have been a major focus of CP investigators; to move forward, we must seek a deeper understanding of why these factors convey information about increased risk.

- Preconception factors, including maternal obesity and age, should be considered because they can modify the relationships between $\mathrm{CP}$ and other factors that occur later in pregnancy.

- Two-hit and multi-hit models that consider accumulation of risk factors can identify a synergistic increase in the risk of $\mathrm{CP}$, but the time order and clinical relevance of the model components must be established.

\section{Apgar score}

A scoring system to predict the need of newborn babies for medical attention; the overall score is composed of scores for heart rate, respiratory effort, muscle tone, response to stimulation and skin

colouration.

Oligohydramnios A pregnancy complication characterized by low amniotic fluid levels.
1.25 cases per 1,000 children between 1999 and 2017 has been reported ${ }^{33,34}$, although ascertainment methods for these reports might have differed from the long-standing registers used in Australia and Europe.

The reported prevalence of CP in South Korea, Japan and India is $2-3$ cases per 1,000 live births ${ }^{35-37}$, but figures greater than 3 cases per 1,000 live births in Taiwan ${ }^{38}$, Egypt $^{39}$ and Uganda ${ }^{40}$ have been reported in the past few years. Some evidence suggests that rates in rural Africa are much higher ${ }^{41}$. New CP registers are emerging in Bangledesh $^{42}$, Mexico ${ }^{43}$ and Jordan ${ }^{44}$, and hospital-based surveillance is being developed in Vietnam ${ }^{45}$.

\section{Major aetiological factors}

The first systematic clinical descriptions of $\mathrm{CP}$ were authored in the 1840s by the orthopaedic practitioner W. J. Little ${ }^{46,47}$. Little's assertion that nearly all cases of what he called spastic rigidity of newborn children resulted from preterm birth or asphyxia at birth has left an enduring mark on subsequent thinking about the aetiology of CP. Sigmund Freud, in his first career as a child neurologist, cautioned against assuming that these two factors were fully causal ${ }^{48-50}$, but only in the latter half of the 20th century did research begin to illustrate the complex nature of these associations.

Nevertheless, Little's insight that the perinatal period was important to the pathogenesis of CP has been supported by subsequent research. Therefore, in this section, we begin by considering the two factors identified by Little before reviewing factors related to preconception, pregnancy and the perinatal period. A comprehensive review of the risk factors for $\mathrm{CP}$ is available elsewhere ${ }^{51}$.

\section{Birth complications}

The obstetric literature from the 20th century is rife with examples of physical trauma in labour, sometimes exacerbated by instrumented deliveries or severe asphyxia in labour and delivery, all of which are capable of causing brain injuries in children that could lead to $\mathrm{CP}^{52}$. However, these events were not placed in an appropriate statistical context until the National Collaborative Perinatal Project (NCPP) study of $\sim 50,000$ children born during 1959-1966. The NCPP provided compelling evidence that clinical indicators of birth asphyxia (for example, fetal bradycardia, a low Apgar score and delayed time to first breath) occurred in only a minority of children who had $\mathrm{CP}^{53}$ and rarely led to $\mathrm{CP}$ when they occurred. Approximately $70 \%$ of children with CP had Apgar scores of $\geq 7$ at 5 min after birth, and $95 \%$ of children with a normal birthweight and an Apgar score of $0-3$ at $5 \mathrm{~min}$ after birth were free from major disability at early school age. These findings made it clear that birth asphyxia was not the dominant cause of $\mathrm{CP}$ that many clinicians and the lay public had assumed. A convenience survey of clinicians (largely paediatricians and obstetricians) shortly after the NCPP publications found that the average estimate of the risk of $\mathrm{CP}$ after a low Apgar score was $40 \%$, eightfold higher than the $5 \%$ risk identified by the $\mathrm{NCPP}^{54,55}$.

The NCPP reinforced a finding noted by many students of birth asphyxia that the risk of CP is markedly elevated by the presence of abnormal neurological signs in the newborn period, most notably seizures, an inability to suck and breathing difficulties, which together indicate the syndrome of neonatal encephalopathy. This syndrome is often assumed to be the consequence of so-called hypoxic-ischaemic brain damage but can occur in the absence of markers of distress during labour and might even have a closer relationship to pre-labour factors ${ }^{56,57}$. Low Apgar scores, delayed onset of respiration, and seizures might be signs of birth asphyxia, but they are neurological findings themselves and can reflect brain damage that was present before birth. Ellenberg and Nelson have argued that the attribution of CP to birth asphyxia often results from the conflation of the consequences of factors that underlie both $\mathrm{CP}$ and birth asphyxia $^{58,59}$, and point out that placental pathology and markers of infection often precede abnormal fetal heart patterns ${ }^{60}$ and low Apgar scores ${ }^{61}$.

Breech vaginal delivery is now avoided in most HICs owing to an assumed risk of birth asphyxia and later CP. The NCPP indeed found an elevated risk of $\mathrm{CP}$ for normal-weight babies who were in the breech position in utero, but the risk was the same whether the baby was born vaginally or by Caesarian section ${ }^{53,62}$. Breech position at term can reflect fetal abnormalities that preceded the onset of labour, including abnormal maternal thyroid function ${ }^{63}$, fetal growth restriction (FGR), oligohydramnios, gestational diabetes and fetal anomalies ${ }^{64}$. In randomized trials, mortality and short-term morbidity associated with breech presentation were reduced by Caesarian section, but long-term neurodevelopmental outcomes were unaffected ${ }^{65}$.

\section{Gestational age and its correlates}

Children born preterm account for one-third to one-half of CP diagnoses in HICs, although this proportion is much lower in low-income countries (LICs), where mortality of very preterm babies remains high ${ }^{40}$. The more preterm the newborn baby, the higher the risk of $\mathrm{CP}$; the prevalence of $\mathrm{CP}$ reaches $\sim 10 \%$ among infants who are born before 28 weeks of gestation, a prevalence that is $\sim 50$-fold higher than that among children born at term ${ }^{66,67}$. 

"The condition of spastic rigidity of
the limbs of newborn children."
(Little, 1861)

\section{"A paralysis of cerebral origin occurring in the first six years of life. It is always a hemiplegia, and the cases which affect both sides of the body will be found to be no exception to this rule, but are simultaneous lesions upon the hemispheres." (Wilson, 1916) \\ "Cerebral palsy is a descriptive term applied to a group of motor disorders of young children, in whom full function of one or more limbs is prevented by paresis, involuntary movement, or incoordination." (Balf and Ingram, 1955)}

"Cerebral palsy is a persistent but not unchanging disorder of movement and posture, appearing in the early years of life and due to a non- progressive disorder of the brain, the result of interference during its development." (The Little Club, 1958 (Bax, 1964))

"A disorder of movement and posture due to a defect or lesion of the immature brain." (Bax, 1964)

"Cerebral palsy is the result of a lesion or maldevelopment of the brain, non-progressive in character and existing from earliest childhood. The motor deficit finds expression in abnormal patterns of posture and movement, in association with an abnormal postural tone," (Bobath, 1969)

"Cerebral palsy is a descriptive term for a collection of nonprogressive neuromotor disorders of central origin that become manifest early in life and are not the result of a recognized cerebral malformation." (Paneth, 1986)

"A group of permanent disorder of the development of movement and posture, causing activity limitation, that are attributed to non-progressive disturbances that occurred in the developing fetal or infant brain. The motor disorders of cerebral palsy are often accompanied by disturbances of sensation, perception, cognition, communication, and behaviour, by epilepsy, and by secondary musculoskeletal problems." (Rosenbaum et al., 2007)

Fig. 1 | Definitions of cerebral palsy over time. The definition of cerebral palsy has changed several times since 1861, and the most recent definition was described in 2007.
Much research has been devoted to identifying the factors that place preterm infants at the greatest risk of $\mathrm{CP}$; the numerous factors that have been studied include organ immaturity, lack of hormones and growth factors, metabolic factors and environmental toxins, infection and inflammation, physiological instability, medical interventions and pregnancy-related complications ${ }^{68}$. The most strongly associated indicators of CP risk in preterm infants are cranial ultrasonography observations in the first few weeks of life ${ }^{69}$. Lesions that indicate white matter injury - usually seen as echolucency and ventricular enlargement - are associated with a substantially increased risk of $\mathrm{CP}^{70}$, whereas isolated germinal matrix and ventricular haemorrhage, which are more common than white matter injury in preterm infants, are associated with a much lower risk of $\mathrm{CP}^{71-76}$.

Mechanical ventilation is widely used for children who are born very preterm and has been linked to $\mathrm{CP}^{70,77}$. The effects of mechanical ventilation on risk are confounded, as its use is an indicator of illness severity $^{78}$, but animal models and observational studies have provided evidence that mechanical ventilation can cause systemic inflammation and lung damage and can alter blood gas levels in ways that might be detrimental to the perinatal brain ${ }^{79-81}$. Ventilator settings that produce hypocapnia have caused particular concern because they have been associated with brain damage at autopsy and with an increased risk of $\mathrm{CP}^{82-88}$. Antenatal administration of steroids during preterm labour to stimulate lung maturation has been associated with a reduced risk of $\mathrm{CP}^{89}$; by contrast, postnatal administration of steroids has raised concerns about an increase in $\mathrm{CP}^{90,91}$.

Intermittent or sustained systemic inflammation in which single ${ }^{92}$ or multiple inflammation-related proteins are persistently upregulated ${ }^{93}$ in the newborn period has been associated with a twofold to threefold increase in the risk of CP in babies born before 28 weeks of gestation. Studies of infants who are born at a weight $\leq 1,000 \mathrm{~g}$ yield similar evidence ${ }^{94}$. Insufficient blood levels of neurotrophic and/or angiogenic proteins also seem to influence the risk of CP and other neurodevelopmental disorders in some settings. For example, transient hypothyroxinaemia, a common complication of preterm delivery and a correlate of low birthweight ${ }^{95-98}$, occurs most often in the smallest and sickest of neonates ${ }^{96-105}$, and some observational studies have found that neonatal thyroid hormone deficits are linked to $\mathrm{CP}$, behavioural problems and lower cognitive performance assessed at school age or in adolescence ${ }^{106-110}$, although other studies have not ${ }^{111,112}$. For example, a nationwide Dutch cohort study of infants born very preterm and/or with very low birthweights showed that relative hypothyroxinaemia (defined as values $>1$ s.d. below the mean) was associated with psychomotor developmental delay at 2 years corrected age $^{109}$, neurological dysfunction assessed at the age of 5 years, and school failure at age 9 years ${ }^{113}$. A population-representative study of 1,105 children born with a weight of $<2,000 \mathrm{~g}$ similarly found a fourfold increase in the risk of CP in newborn children with thyroid hormone levels $>2.6$ s.d. below the state norm compared with children with normal levels after adjustment for gestational age and multiple prenatal, perinatal and 
Table 1 | Trends in the prevalence of cerebral palsy overall and by birthweight or gestational age at delivery

\begin{tabular}{|c|c|c|c|c|}
\hline Location (study) & Prevalence group & Years & $\begin{array}{l}\text { Observed prevalence (per } 1,000 \\
\text { in specified prevalence group) }\end{array}$ & $95 \% \mathrm{Cl}$ \\
\hline \multirow{11}{*}{$\begin{array}{l}\text { Northern Alberta, Canada } \\
\text { (Robertson et al. } .^{30} \text { ) }\end{array}$} & \multirow[t]{3}{*}{ All live births } & 2008 & 2.38 & $2.19-2.57$ \\
\hline & & 2009 & 2.26 & $2.10-2.44$ \\
\hline & & 2010 & 1.89 & $1.70-2.10$ \\
\hline & \multirow[t]{2}{*}{ Birthweight $<1,000 \mathrm{~g}$} & $1985-1988$ & 98.4 & $59.5-137.4$ \\
\hline & & 2008-2010 & 40.1 & $34.5-45.7$ \\
\hline & \multirow[t]{2}{*}{ Birthweight $1,000-1,499 \mathrm{~g}$} & 1985-1988 & 70.7 & $43.8-97.6$ \\
\hline & & $2008-2010$ & 22.7 & $19.3-26.0$ \\
\hline & \multirow[t]{2}{*}{ Birthweight $1,500-2,499 \mathrm{~g}$} & $1985-1988$ & 11.0 & $7.9-14.1$ \\
\hline & & $2008-2010$ & 6.7 & $5.9-7.5$ \\
\hline & \multirow[t]{2}{*}{ Birthweight $\geq 2,500 \mathrm{~g}$} & 1985-1988 & 1.7 & $1.6-1.8$ \\
\hline & & 2008-2010 & 1.3 & $1.2-1.4$ \\
\hline \multirow{8}{*}{$\begin{array}{l}\text { Europe } \\
\text { (Sellier et al. }{ }^{27} \text { ) }\end{array}$} & \multirow[t]{2}{*}{ Birthweight $<1,000 \mathrm{~g}$} & 1980 & 40.9 & $12.1-97.3$ \\
\hline & & 2005 & 38.2 & $26.0-53.8$ \\
\hline & \multirow[t]{2}{*}{ Birthweight $1,000-1,499 \mathrm{~g}$} & 1980 & 70.9 & $41.7-110.9$ \\
\hline & & 2005 & 35.9 & $26.6-47.2$ \\
\hline & \multirow[t]{2}{*}{ Birthweight $1,500-2,499 \mathrm{~g}$} & 1980 & 8.5 & $5.4-12.7$ \\
\hline & & 2005 & 6.2 & $4.9-7.8$ \\
\hline & \multirow[t]{2}{*}{ Birthweight $\geq 2,500 \mathrm{~g}$} & 1980 & 1.2 & $0.9-1.5$ \\
\hline & & 2005 & 0.9 & $0.8-1.0$ \\
\hline \multirow{12}{*}{$\begin{array}{l}\text { Japan } \\
\text { (Touyama et al. }{ }^{32} \text { ) }\end{array}$} & \multirow[t]{2}{*}{ All live births } & 1988-1997 & 1.8 & $1.6-2.0$ \\
\hline & & 1998-2007 & 0.97 & $0.94-0.99$ \\
\hline & \multirow[t]{2}{*}{ Birthweight $<1,000 \mathrm{~g}$} & 1988-1997 & 65.5 & $46.1-90.3$ \\
\hline & & 1998-2007 & 108.7 & $83.9-138.5$ \\
\hline & \multirow[t]{2}{*}{ Birthweight 1,000-1,499g } & 1988-1997 & 89.9 & $72.2-110.6$ \\
\hline & & $1998-2007$ & 74.6 & $59.6-92.3$ \\
\hline & \multirow[t]{2}{*}{ Birthweight $1,500-1,999 \mathrm{~g}$} & 1988-1997 & 28.6 & $22.0-36.6$ \\
\hline & & 1998-2007 & 21.0 & $15.7-27.3$ \\
\hline & \multirow[t]{2}{*}{ Birthweight 2,000-2,499g } & 1988-1997 & 2.4 & $1.6-3.5$ \\
\hline & & 1998-2007 & 3.0 & $2.1-4.0$ \\
\hline & \multirow[t]{2}{*}{ Birthweight $\geq 2,500 \mathrm{~g}$} & 1988-1997 & 0.6 & $0.5-0.7$ \\
\hline & & 1998-2007 & 0.5 & $0.4-0.7$ \\
\hline \multirow{6}{*}{$\begin{array}{l}\text { USA } \\
\text { (Durkin et al. }{ }^{26} \text { ) }\end{array}$} & \multirow[t]{3}{*}{ 8-year-old children } & 2006 & 3.5 & $3.2-3.9$ \\
\hline & & 2008 & 3.2 & $2.9-3.5$ \\
\hline & & 2010 & 2.9 & $2.6-3.2$ \\
\hline & \multirow{3}{*}{$\begin{array}{l}\text { 8-year-old children, excluding those with } \\
\text { a documented post-neonatal cause }\end{array}$} & 2006 & 3.2 & $2.9-3.5$ \\
\hline & & 2008 & 3.0 & $2.7-3.3$ \\
\hline & & 2010 & 2.6 & $2.3-2.9$ \\
\hline \multirow{12}{*}{$\begin{array}{l}\text { Victoria, Australia } \\
\text { (Reid et al. }{ }^{3} \text { ) }\end{array}$} & Gestational age $\geq 37$ weeks & 1983-1991 & 1.2 & Not available \\
\hline & & $1992-2000$ & 1.2 & Not available \\
\hline & & 2001-2009 & 1.0 & Not available \\
\hline & Gestational age $32-36$ weeks & 1983-1991 & 5.3 & Not available \\
\hline & & $1992-2000$ & 3.8 & Not available \\
\hline & & 2001-2009 & 4.2 & Not available \\
\hline & Gestational age $28-31$ weeks & 1983-1991 & 41.5 & Not available \\
\hline & & $1992-2000$ & 40.0 & Not available \\
\hline & & 2001-2009 & 32.4 & Not available \\
\hline & Gestational age $<28$ weeks & 1983-1991 & 92.1 & Not available \\
\hline & & $1992-2000$ & 102.5 & Not available \\
\hline & & 2001-2009 & 70.6 & Not available \\
\hline
\end{tabular}


early and late neonatal variables ${ }^{110}$. In a similarly large study of infants born with very low birthweight, transient hypothyroxinaemia was associated with a twofold greater risk of white matter damage, a key antecedent of $\mathrm{CP}$, after adjustment for gestational age and various measures of illness severity ${ }^{114}$. Whether the association between neonatal thyroid hormone deficits and CP is truly causal can be determined only with a randomized trial of thyroid hormone supplementation ${ }^{95,115}$.

Similarly, severe maternal iodine deficiency, which presumably leads to maternal and thus fetal hypothyroxinaemia, is associated with cognitive impairments and neurological deficits that resemble $\mathrm{CP}^{116}$. Iodine deficiency remains an important remediable cause of cognitive, neurosensory and motor impairment in several parts of the world ${ }^{117}$.

\section{Preconception and early gestation}

Genetics. Familial clustering of CP has been described: three studies since 2007 have indicated that the relative risk of CP for the sibling of a child with CP is four ${ }^{118}$, five $^{119}$ and nine ${ }^{120}$, respectively. However, even these relative risks translate to a small absolute risk of $\mathrm{CP}$ of $1-2 \%$. Copy number variants and mutations in single genes have been implicated in $\mathrm{CP}$, but these findings are limited by small numbers of patients, genetic heterogeneity and a paucity of validation studies ${ }^{121}$. Whole-exome sequencing has revealed several potentially disease-causing gene variants, but functional and pathway studies are needed to validate these findings ${ }^{122}$.

Among the most studied genetic risk factors is $A P O E$ genotype. APOE encodes apolipoprotein $\mathrm{E}$ (ApoE), a lipid transport protein that is abundant in the brain; the $A P O E^{\star} \varepsilon 4$ allele has been associated with several neurological conditions, most notably Alzheimer disease. Studies of $A P O E$ genotype and the risk of $C P$ have produced a variety of results. The $A P O E^{*} \mathcal{E} 4$ allele has been associated with an elevated relative risk of $\mathrm{CP}$ in one Brazilian study ${ }^{123}$ and two studies conducted in the USA ${ }^{124,125}$, one of which also indicated an elevated risk among carriers of the $A P O E^{\star} \varepsilon 2$ allele. In a large, population-based study conducted in Norway, the $A P O E^{\star} \varepsilon 4$ allele was associated with an increased severity of $\mathrm{CP}^{126}$, whereas the $A P O E^{\star} \varepsilon 2$ or $A P O E^{\star} \varepsilon 3$ alleles and the s59007384 polymorphism in the TOMM40 gene (which is located on chromosome 19 close to $A P O E$ ) were associated with reduced severity of $\mathrm{CP}^{127}$. However, in a second Brazilian study, an elevated risk of $C P$ was associated only with the $A P O E^{\star} \varepsilon 2$ allele ${ }^{128}$, and a Norwegian family study identified $A P O E^{\star} \varepsilon 3$ to be the $A P O E$ allele most closely linked with $\mathrm{CP}^{129}$. Furthermore, three much larger studies - two conducted in Australia ${ }^{130,131}$ and one in China ${ }^{132}$ - found no association of any APOE allele with the risk of CP.

In a review published in 2009 (REF. ${ }^{133}$ ), an association between certain thrombophilia-related genes and CP caused by intrauterine strokes was suggested, but the literature on this area is sparse. A subsequent Australian study of candidate maternal or fetal thrombophilia-related genes that included 587 children with CP and their mothers and 1,154 healthy mother and child pairs identified no significant association of
$\mathrm{CP}$ with these genes or any others studied after correction for multiple comparisons ${ }^{131}$. A nested case-control study conducted in California, USA, that was intended to replicate the previously identified links between several polymorphisms and CP in 127 affected children indicated an association of $\mathrm{CP}$ with the inducible nitric oxide synthase (iNOS)-231 T allele (which is involved in inflammation) and the $A P O E^{\star} \varepsilon 4$ allele. Both associations were statistically significant at the 0.04-0.05 level, but neither remained significant after adjustment for multiple comparisons ${ }^{125}$.

Multiple births. The prevalence of CP among twins is fourfold higher than among singletons ${ }^{134,135}$, and this excess is greater for higher-order multiples ${ }^{136,137}$. Nearly all of this excess risk is accounted for by the lower gestational age and lower birthweights associated with multiple births ${ }^{138,139}$, but the risk of CP is slightly higher even for full-term multiple births than for singletons born at term ${ }^{140-142}$. CP in one twin is associated with a greatly increased risk of $\mathrm{CP}$ in their co-twin: in one analysis of $>20,000$ twin sets in Norway, the twin of a child with CP had a 15-fold higher risk of CP than singletons ${ }^{120}$. Despite this elevated risk, fewer than $12 \%$ of twin sets are concordant for $\mathrm{CP}^{143}$. In the only two published series of identical twins, concordance for CP was $18-40 \%{ }^{144,145}$.

Little is known about the factors that contribute to disparate susceptibility to $\mathrm{CP}$ between co-twins, although factors such as birth order, birthweight discordance, gender and chorionicity have been examined $^{145-148}$. Monochorionic placentation is thought to convey a higher risk than dichorionic placentation ${ }^{149}$, as for the risk of congenital anomalies ${ }^{150}$, but information on zygosity and chorionicity is rarely known for children with $\mathrm{CP}$, making this thesis difficult to investigate in most databases. Genetics could have a role, but other factors are more strongly associated; for example, the death of a co-twin in utero is associated with a substantially higher risk of CP in the surviving twin ${ }^{139,151,152}$.

Socio-economic status and correlates. Several studies have demonstrated that children who are socially disadvantaged are at higher risk of CP than those who are not $^{138,139,153-157}$. For example, a higher prevalence of CP has been identified among African-American children than among other children ${ }^{138,139}$, but this observation was only partially explained by differences in level of maternal education and was largely a function of higher rates of preterm birth among socially disadvantaged women $^{26,154}$. However, although multiple indicators of social disadvantage are associated with an increased risk of $\mathrm{CP}$, these relationships seem to be moderated or mediated by differences in gestational age, birthweight and/or their correlates (for example, maternal obesity ${ }^{139,153,154}$, which is more common among women of lower socio-economic status ${ }^{158-161}$ ).

Analysis of a database of 6 million births in California, USA, revealed a dose-response relationship between pre-pregnancy obesity and CP: the relative risk of CP for the children of mothers classed as morbidly obese (2.7) was significantly higher than for those whose mothers were classed as obese (1.3) ${ }^{162}$. Large studies conducted 
in South Carolina (USA) ${ }^{163}$, Norway and Denmark ${ }^{164}$, and Sweden ${ }^{25}$ produced similar results. In the Swedish study, the association was limited to infants born at term. Putative mechanisms for this consistent finding include the excess inflammation seen in obesity ${ }^{165,166}$, placental dysfunction ${ }^{167,168}$ and thyroid hormone deficits ${ }^{169,170}$. However, maternal obesity does not seem to be associated with an increased risk of $\mathrm{CP}$ among children who are born before the 28th week of gestation ${ }^{171}$.

\section{Pregnancy and congenital anomalies}

Fetal growth restriction and maternal pre-eclampsia. Several studies have identified associations of CP with FGR in infants born at term or near term ${ }^{172-174}$, in infants born late or moderately preterm ${ }^{174}$ or in infants born at any gestational age $\mathrm{e}^{175}$. The most definitive data come from the pooling of several national CP registers referred to as Surveillance of Cerebral Palsy in Europe, which revealed a significant fourfold to sixfold excess risk of CP among infants with FGR who were born at $32-42$ weeks of gestation ${ }^{176}$. This finding is consistent with evidence from an Australian reconstructed population cohort study in which being small for gestational age and pregnancy-induced hypertension were associated with a twofold to ninefold increase in the risk of $\mathrm{CP}$ among all infants born after 27 weeks of gestation ${ }^{175}$.

FGR and maternal pre-eclampsia have both been associated with a reduced risk of $\mathrm{CP}$ in studies of children born with low birthweight ${ }^{177,178}$. However, birthweight is inextricably linked with gestational maturity, which is strongly associated with CP; therefore, studies of children with a birthweight below a specified threshold will include growth-restricted newborn babies from more mature gestational age strata, who have a lower risk of $\mathrm{CP}$ than infants of lower gestational ages ${ }^{179}$. Population-wide studies that include infants of all gestational ages do not reproduce this anomaly ${ }^{118,176,180}$.

This issue particularly affects studies of pre-eclampsia and CP. A study conducted in Australia showed that pre-eclampsia seems to provide a strong protective effect against CP in infants with low birthweights, but that no association with $\mathrm{CP}$ is observed in a sample defined by truncation of gestational age rather than of birthweight ${ }^{181}$. Confounding of FGR with gestational age seems to be reduced, if not completely avoided ${ }^{182}$, by selecting samples of preterm infants on the basis of truncated gestational age rather than truncated birthweight, a practice that is becoming more common ${ }^{183}$ but is still not universal ${ }^{184}$.

Infection. Maternal infections can lead to CP by transmission of pathogens to the fetus (even without a detectable maternal inflammatory response $\mathrm{e}^{185}$ ) and by induction of persistent systemic inflammation that can sensitize the brain to subsequent insults ${ }^{186-188}$. Infections such as toxoplasmosis, rubella, cytomegalovirus and herpes simplex virus during pregnancy have been associated with increased risks of $\mathrm{CP}^{189-191}$, but these agents account for only a small fraction of CP cases in HICs. A subtype of $\mathrm{CP}$ that is associated with microcephaly has been reported as a result of perinatal mother-to-child chikungunya virus infection ${ }^{192}$. Zika virus infection in utero can damage the fetal brain ${ }^{193}$, but the magnitude of the contribution of Zika virus to $\mathrm{CP}$ is not yet understood. To date, seven case-series and one cohort study have examined whether children with clinical evidence of congenital Zika virus infection exhibit early indicators of motor dysfunction and epilepsy; in total, 54\% of these children had seizures and all of them were judged to have abnormal motor development after follow-up periods of 3-12 months ${ }^{194}$.

The presence of several nonspecific indicators of infection, such as maternal fever ${ }^{195-197}$, maternal receipt of antibiotics $^{198}$ and chorioamnionitis ${ }^{197,199,200}$, close to the time of delivery have been linked to an increased risk of CP. Infections earlier in pregnancy have often been associated with CP as well ${ }^{201-204}$, but not all studies agree ${ }^{205}$.

Birth defects. Two lines of evidence indicate that developmental aberrations similar to those that cause birth defects are involved in an appreciable fraction of CP cases. First, imaging studies of children with CP have shown that cerebral malformations, which are often unsuspected before CT or MRI, are not infrequent. One systematic review of the topic showed that such malformations were found in $10 \%$ of children with CP, mostly in children who were born at term ${ }^{206}$. Several different brain developmental defects seem capable of producing CP, especially neuronal migration disorders ${ }^{207}$, such as schizencephaly ${ }^{208}$ and polymicrogyria ${ }^{209}$. Interestingly, cytomegalovirus infection might underlie these neuronal migration disorders in some instances ${ }^{191,210}$. In general, the brain malformations involved seem to arise from a wide variety of genetic and environmental insults, are not rare in $\mathrm{CP}$ and can be congenital or acquired ${ }^{211}$. Intrauterine infections are associated with congenital anomalies; the most recently identified association is with Zika virus infection ${ }^{212,213}$. A detailed review of the development of these abnormalities is available elsewhere ${ }^{51}$.

The second line of evidence is the frequent presence of malformations outside the nervous system in children with CP. The NCPP showed that such malformations are observed threefold more often in children with $\mathrm{CP}$ than in healthy children, a finding that has been confirmed in subsequent studies ${ }^{214-216}$. Hypertensive disorders of pregnancy are associated with congenital malformations, in particular congenital heart defects ${ }^{217,218}$, as are indicators of thyroid dysfunction ${ }^{219-221}$; each of these factors are associated with FGR, CP and other neurodevelopmental disorders (possibly reflecting mitochondrial dysfunction $^{222}$ ). A study conducted in Australia found that 53\% of children with CP and severe FGR who were born at or near term had a major birth defect ${ }^{180}$.

\section{Perinatal risk factors}

Perinatal stroke. Perinatal stroke, which occurs between late gestation and 28 days after birth, might account for as much as half of hemiplegic CP in infants born at term ${ }^{223,224}$, whereas children with other CP subtypes often have multifocal or more diffuse injury. The most common form of perinatal stroke is thrombosis in the arterial distribution, usually in the middle cerebral artery, but periventricular venous infarction can 
contribute $^{225,226}$. Most perinatal strokes are ischaemic, but haemorrhagic strokes can occur, sometimes as a complication of ischaemic injury ${ }^{227}$.

The causes of perinatal stroke are largely unknown. Perinatal stroke can be a complication of congenital heart disease $^{228}$ and bacterial or viral meningitis ${ }^{229}$. Placental factors such as chorioamnionitis ${ }^{199}$, prolonged rupture of membranes ${ }^{230}$ and placental thrombosis ${ }^{231}$ have also been implicated. Pre-eclampsia and FGR are also risk factors ${ }^{223}$. Genetic predispositions to thrombophilia have been described above.

Kernicterus. Neonatal jaundice is the most common complication of the newborn period, usually caused by unconjugated hyperbilirubinaemia ${ }^{232}$. Unconjugated bilirubin crosses the blood-brain barrier in the first days of life and can damage several parts of the brain, particularly the basal ganglia and acoustic nuclei. The yellow staining seen at autopsy in this condition is the origin of the neuropathological term kernicterus. Symptoms of bilirubin-associated encephalopathy in newborn babies include lethargy, impaired tone, cyanosis, vomiting and absence of the suck reflex ${ }^{233}$. Chronic bilirubin encephalopathy manifests as aberrant processing disorders (particularly hearing impairment) and CP.

$\mathrm{CP}$ that results from kernicterus is typically choreoathetotic or dystonic, indicating damage to extrapyramidal structures ${ }^{233}$. In preterm infants, kernicterus can occur with bilirubin levels that would not pose risks to infants born at term. Kernicterus was once a common cause of $\mathrm{CP}^{234,235}$, but in HICs, the number of cases of $\mathrm{CP}$ associated with kernicterus has declined substantially owing to prevention and better management of newborn hyperbilirubinaemia. Kernicterus remains a notable cause of CP in LICs ${ }^{236,237}$.

\section{Prevention of cerebral palsy Magnesium sulfate}

Case-control studies conducted in the 1990s suggested that magnesium sulfate $\left(\mathrm{MgSO}_{4}\right)$, which is administered in pregnancy to treat pre-eclampsia and in preterm labour to slow contractions, reduces the risk of $\mathrm{CP}$ in infants born preterm ${ }^{238-240}$. Modest support for this hypothesis was provided by some cohort studies ${ }^{240}$ but not others ${ }^{241,242}$. A concern in all such observational studies was confounding by indication ${ }^{78}-$ the possibility that recipients of $\mathrm{MgSO}_{4}$ were at an inherently lower risk of $\mathrm{CP}$, given that maternal pre-eclampsia has been associated with a lower risk of CP in studies of infants with truncated birthweights ${ }^{178,243-245}$. However, the benefit of $\mathrm{MgSO}_{4}$ was clearly demonstrated by the BEAM trial, in which the risk of CP in infants born before 32 weeks of gestation and who were randomly assigned to receive $\mathrm{MgSO}_{4}$ during labour was nearly $40 \%$ lower than among infants of the same gestational age who received placebo ${ }^{246,247}$. Two meta-analyses of randomized trials converge on an estimated $30 \%$ reduction in the risk of CP as a result of $\mathrm{MgSO}_{4}$ administration ${ }^{248-250}$. A similar reduction was reported in a meta-analysis of observational studies ${ }^{251}$.

Canadian, British, American and Australian obstetric societies and bodies have issued clinical practice guidelines that recommend $\mathrm{MgSO}_{4}$ for fetal neuroprotection in the setting of imminent preterm birth at $<32-34$ weeks of gestation ${ }^{252}$. Implementation of these guidelines might be a contributor to the reduction in $\mathrm{CP}$ prevalence among children who have low birthweights in many $\mathrm{HICs}^{3}$. Nevertheless, $\mathrm{MgSO}_{4}$ can cause maternal adverse effects ${ }^{248}$, such as respiratory depression, hypotension and confusion, and questions remain about the optimal timing of administration ${ }^{253}$, dosage d53,254 $^{25 d}$ duration $^{255,256}$, and modifiers of therapeutic efficacy (for example, maternal obesity) 257,258. $^{2}$

\section{Therapeutic hypothermia}

A series of randomized trials with consistent results have shown that lowering of body and/or head temperature by $2^{\circ} \mathrm{C}$ for $48 \mathrm{~h}$, beginning in the first few hours after birth, can reduce the risk of and mortality from $\mathrm{CP}$ in children who are born after 36 weeks of gestation and who have hypoxic-ischaemic encephalopathy ${ }^{259,260}$. All trials enrolled infants with signs of encephalopathy and indicators of fetal and immediate neonatal distress that are thought to reflect asphyxia. Therapeutic hypothermia is now used internationally ${ }^{261,262}$ and has become the standard of care in many centres in HICs. Trials are underway to determine the safety and efficacy of cooling therapy in low-income and middle-income countries (LMICs) ${ }^{263}$ and in infants whose treatment was delayed beyond the first few hours. Whether head cooling would be effective in infants with neonatal encephalopathy that is not associated with evidence of hypoxia or ischaemia is an open question.

Among infants who are born at term or late preterm and who have moderate to severe encephalopathy, hypothermia improves survival and neurodevelopmental outcomes, including the development of $\mathrm{CP}$, at 18 months of age $^{257}$, but CP is not eliminated altogether by this treatment. Children with severe newborn encephalopathy remain at increased risk of severe neurodevelopmental impairment despite the treatment ${ }^{264}$. Preterm birth and comorbid exposure to clinical or histological chorioamnionitis (or the correlates of each) are associated with a reduced response to hypothermia ${ }^{265}$.

Attempts to combine cooling with adjunctive therapies to provide additional benefits are underway ${ }^{266,267}$. For example, 1,000 U/kg erythropoietin administered intravenously in three doses (immediately after birth, at $24 \mathrm{~h}$ and 1 week later) in conjunction with hypothermia is well tolerated and produces plasma concentrations that are neuroprotective in animals. However, a large efficacy trial is needed to determine whether this add-on therapy improves outcomes in infants undergoing hypothermia $^{268}$.

\section{Investigational therapies}

Various other therapies for CP have been tested and are under investigation. Caffeine is one of the most commonly prescribed medications in neonatal intensive care units as a treatment for apnoea ${ }^{269}$. A Canadian multicentre trial of caffeine in premature infants with apnoeic episodes indicated a reduction in the risk of motor and cognitive impairment with the treatment. The finding was statistically significant at 18 months ${ }^{270}$ but not at 5 years ${ }^{271}$. 
Melatonin treatment in combination with hypothermia has been compared with hypothermia alone in one small trial ( $n=15$ in each arm) in infants with birth asphyxia ${ }^{272}$. The results hinted that melatonin improved survival during 6 months of follow-up and lowered the risk of seizures and indicators of white matter injury assessed at 2 weeks after birth. A trial of melatonin in preterm birth before 28 weeks of gestation is ongoing ${ }^{273}$.

Erythropoietin has been studied in four randomized trials in infants born very preterm or who are very small. The treatment seemed to reduce the proportion of children with Bayley Mental Development Index scores $<70$ at follow-up, but the treatment did not affect the risk of $\mathrm{CP}^{274}$

Finally, stem cell therapies for CP are also under investigation. These studies are not yet at a sufficiently advanced stage to discern the effects of the treatment on $\mathrm{CP}^{275,276}$, but evidence from small studies hints at benefits for some children ${ }^{277}$.

\section{Early diagnosis and intervention}

The age at which a CP diagnosis is validly, reliably and fully ascertained by ruling out transient or progressive motor problems is controversial. Long-standing evidence indicates that a proportion of motor problems detected before the age of 1 year (for example, developmental delay, coordination problems and transient dystonia) resolve by school age without intervention ${ }^{278-282}$ and that a small fraction of motor disability in children of school age is the result of progressive motor pathology (for example, in metabolic disorders ${ }^{283}$ ), neither of which fits the current model of CP. Clinical prediction models and neuroimaging have been used to diagnose CP before the age of 2 years, but further research is necessary.

\section{Clinical prediction studies}

Few studies have repeatedly assessed CP status over the first several years of childhood among the general population. Evidence from two studies suggests that a diagnosis of $\mathrm{CP}$ at or before a child's first birthday is unreliable ${ }^{280,281}$. In the largest study to date, which included 37,000 children, $45 \%$ of those who were diagnosed with definite $\mathrm{CP}$ at their first birthday 'outgrew' their motor problems by the age of 7 years ${ }^{280}$, and fewer than $3 \%$ of infants who were thought to have probable $\mathrm{CP}$ at age 1 year had CP at age 7 years. It is important to distinguish between CP diagnosed at an early age solely on the basis of neurological findings and $\mathrm{CP}$ accompanied by clear evidence of a disability. Thus, a diagnosis made after $\sim 2$ years of age is more reliable ${ }^{284}$, particularly when the motor problems are disabling (for example, an inability to walk five steps unaided or a need for physical assistive devices). However, in a study of children who were born preterm and weighed $<2,000 \mathrm{~g}$ at birth, diagnosis of non-disabling CP was not a stable diagnosis until after 6 years of age $\mathrm{e}^{285}$. This instability of diagnosis at the milder end of CP probably explains why some, but not all, CP registers conduct regular clinical reassessments at the age of 5 years to ensure diagnostic accuracy ${ }^{286}$.
Claims that accurate identification of children who are at high risk of $\mathrm{CP}$ is possible at just a few months of age are increasing in the literature. However, clinical prediction studies have often assessed CP in combination with other disorders or used other proxies for a diagnosis of CP, such as an interim clinical diagnosis of a high risk of CP before a true diagnosis is confirmed ${ }^{287,288}$. A review published in 2017 concluded that CP could be diagnosed on the basis of the absence of so-called jittery movements in infancy ${ }^{287}$, but the conclusions were based largely on expert opinion, most of the reviewed studies defined CP in combination with other motor problems, and none included data beyond the age of 2 years (see the appendix in the review ${ }^{287}$ ). The use of various definitions of 'high risk of CP' has hampered direct comparisons between studies. For example, of 12 studies that focused on motor dysfunction (see a review of these studies ${ }^{288}$ ), the outcome assessed in 6 was CP 'or other disorders', and in 5 the clinical decision relied on clinical impressions, intelligence or development quotients; in only 1 of the 12 was CP assessed alone. In addition, the majority of these studies do not include follow-up of children at or beyond 2 years of age, and most are not population-based or geographically representative of the general population or a targeted high-risk group.

In some studies in Australia and Europe, use of the General Movements Assessment in high-risk patients has indicated a high sensitivity and specificity for the prediction of a high risk of CP. These findings have prompted the Australian investigators to recommend widespread adoption into clinical practice ${ }^{289}$. However, given that decisions about diagnostic tests should be made on the basis of patient benefits ${ }^{289}$, we feel that additional research is needed, as do others ${ }^{290}$. Indeed, although some evidence indicates that early detection and intervention can improve some cognitive outcomes $^{291}$, the improvements observed in motor dysfunction are much more modest ${ }^{287,291}$, and the evidence for a benefit is limited by a dearth of high-quality trials ${ }^{292}$.

\section{Neuroimaging studies}

We have discussed the use of neuroimaging in detail in a previous review ${ }^{293}$, in which we concluded that neuroimaging is not required for diagnosis of $\mathrm{CP}$ because the disorder is based on clinical findings, and the principal contribution of imaging is to the understanding of $\mathrm{CP}$ aetiology and pathogenesis. We also concluded that imaging studies were less informative than they could be, largely because study designs were rarely based on generalizable samples.

Since this previous review, several population-based neuroimaging studies have provided evidence that the occurrence of white matter injury has declined and that of grey matter injury has increased, whereas the prevalence of malformations in children with CP remained about the same. However, the authors of a review of these studies ${ }^{294}$ concluded that a dearth of standardized protocols and terminology were probably responsible for the heterogeneity of these findings (for example, there was no minimum or standard age at assessment).

The well-designed Generation R study of a geographically representative sample from the Netherlands, 
published in 2017, highlighted a diverse array of research questions that can be addressed by merging neuroimaging with developmental neuroscience and epidemiology $\mathrm{y}^{295}$; an example is an ongoing effort to develop growth curves of optimal brain development. Nevertheless, studies of selected populations continue to be more common, and these types of studies were considered in a 2018 systematic review of early MRI for detection of motor outcomes at term-corrected age in children born preterm ${ }^{296}$. This review identified a high sensitivity and specificity of MRI for detection of CP or other motor problems, but the findings were difficult to generalize because not all participants had $\mathrm{CP}$, and few studies were of unselected, sequentially recruited, representative infants. Instead, most were carried out in tertiary centres with high-risk patients, and recruitment rates of eligible infants were as low as $17 \%$ in some settings. Consequently, further research is needed to establish the effect of sample composition ${ }^{297}$ and the clinical relevance of MRI in early identification of CP.

\section{Complexities in cerebral palsy epidemiology Accumulation and interaction of insults}

$\mathrm{CP}$ can often be the result of combined insults, but not all insults are equally influential and some probably have context-specific effects; the importance of timing and co-occurrence of different insults is unclear, although several examples have been studied. The combination of antenatal inflammation with postnatal systemic inflammation is associated with an increased risk of $\mathrm{CP}$ in children born before 28 weeks of gestation ${ }^{298}$, as are combinations of postnatal systemic inflammation and high or low levels of proteins that are related to angiogenesis and thyroid dysfunction ${ }^{299,300}$. FGR and/or very preterm birth seem to make infants particularly susceptible to multiple-hit phenomena that involve white matter injury and its correlates because these infants tend to have more vigorous postnatal inflammatory responses than do other infants ${ }^{301-303}$. Chronic placental inflammation followed by acute fetal inflammation followed by neonatal illness is similarly associated with cerebral white matter injury in infants who are born before 32 weeks of gestation ${ }^{304}$.

Additional evidence that accumulation of insults is involved in CP comes from a population-based study of infants with birthweights $<2 \mathrm{~kg}$ with risk factors associated with ventilator use. This study showed that the risk of CP increased incrementally with addition of three ventilatory risk factors: hyperoxia, hypocapnia and ventilation for longer than expected for gestational age. The presence of one ventilatory risk factor was associated with an $11 \%$ risk of $\mathrm{CP}$, two risk factors were associated with a $35 \%$ risk and three risk factors were associated with a $57 \%$ risk $^{88}$. In a study of over 200,000 pregnancies, pre-eclampsia, neonatal infection, presumed birth asphyxia and neonatal illness were cumulatively associated with an increased risk of $\mathrm{CP}^{213}$. Similarly, a study of nearly 6,000 infants with very low birthweights in Taiwan indicated a strong interaction between sepsis and postnatal hypoxic-ischaemic events. Infants with sepsis alone had a $10 \%$ risk of $\mathrm{CP}$, but adding one, two, three or four events increased the risk of CP to $17 \%, 27 \%, 40 \%$ and $55 \%$, respectively ${ }^{305}$.

\section{Hidden from view}

Although a small fraction of CP is caused by obvious postnatal events, such as meningitis or head trauma, at least $90 \%$ of the factors that predispose infants to CP in HICs are no longer operative and are often no longer detectable after the perinatal period. Furthermore, many prenatal causes are often hidden from view because the inflammatory stimuli that seem to contribute to preterm birth, the silent strokes and the hormonal changes operate under the cover of amnion and uterus. However, a firm diagnosis of CP cannot usually be made until the child's nervous system is mature enough to display the motor deficits that describe CP, usually at about the age of 2 years. By the time a child is diagnosed with $\mathrm{CP}$, the history of the pregnancy and the perinatal period can be reconstructed only from medical records and maternal recall, which are useful but have limitations (for example, recall bias and reliance on clinical notes). Prospective data collection can improve the precision of data about exposures, but to date, few prospective preconception or pregnancy cohort studies have included follow-up of children to school age or beyond to assess neurodevelopmental outcomes. Consequently, delivery and neonatal factors have received much consideration, partly because of the dearth of quality evidence about earlier antecedents of CP. This bias has important implications because pre-pregnancy and early pregnancy risk factors (such as body weight) and their correlates can influence the capacity for delivery-related and postnatal factors to provide information about the risk of $\mathrm{CP}$ (for example, maternal age $)^{306}$.

\section{One disorder or many?}

The relationships between clinical entities that are used as diagnoses and established pathophysiological pathways vary greatly. Some disorders are defined by abnormalities at the molecular level, such as sickle cell anaemia, but many are defined by their clinical appearance ${ }^{307}$ and often represent the common end point of various pathophysiological changes. Use of such disease entities often continues despite recognition of their heterogeneity because the entity is useful in clinical management; for example, whether a stroke was ischaemic or thrombotic matters little for the rehabilitation of a patient.

As discussed above, the term CP includes entities that are apparently caused by multiple pathways, yet the single term persists. Some epidemiologists have referred to 'cerebral palsies' ${ }^{308}$ and the current definition refers to a group of disorders to indicate the heterogeneity ${ }^{309,310}$, but this usage has not taken hold in clinical settings, largely because the traditional phenomenological entity and its observable subdivisions are clinically useful for prognosis and management. Novel classification schemes based on topography have not consistently improved reliability in describing CP subtypes ${ }^{311}$; therefore, the field has moved away from classification according to the underlying impairment and towards a focus on functioning ${ }^{312-315}$. What this trend means for aetiological research remains to be seen. 
The temptation, which is consistent with the current emphasis on precision medicine, is to divide the condition into narrower subdivisions that are more likely to be aetiologically homogeneous. However, when a clinical entity is fairly uncommon, as is the case for CP, creating finer and finer subdivisions makes investigation of aetiology very difficult. Even in the collaborative perinatal project, which included 50,000 participants, analysis did not consider much beyond the diagnosis of CP itself; the only difference emphasized was that between children with birthweights above and below $2,500 \mathrm{~g}\left(\mathrm{REFS}^{53,316,317}\right)$. Two initiatives could help to overcome this difficulty: one is the newly initiated integration of Danish and Norwegian birth cohorts (referred to as MOBAND) $)^{318}$, which aggregates the medical records from 200,000 well-studied pregnancies and births and links them to the national CP registers of those countries, and the other is the Global Pregnancy 'CoLaboratory' ${ }^{319}$ (CoLab; see Related links), a network of investigators from multiple population-based register and cohort studies who seek to facilitate standardization of data collection instruments and study designs and to enable data sharing to solve complex questions about major pregnancy complications and their sequelae. However, no consensus has been reached on the kinds of subdivisions (for example, gestational age at birth, type of motor abnormality or distribution of affected limbs) that would lead to the greatest aetiological insight ${ }^{318}$.

Specificity is problematic for all symptom-based case definition $s^{320}$, and mis-specification of heterogeneous syndromes as singular entities can mask important findings about aetiology ${ }^{321}$, including evidence of therapeutic benefits ${ }^{322}$. Subtypes of a syndrome can be established in three ways. The first is to demonstrate different risk profiles. The second is to establish that the underlying morbid anatomy or pathophysiology differs. The third is to demonstrate that a subset of a disorder can be prevented (as in the case of kernicteric brain damage prevented by control of bilirubin blood levels). In reality, none of these strategies alone will provide a definitive answer about subtypes of $\mathrm{CP}$ because some similarities and differences in the antecedents, neuroanatomy and efficacy of interventions are observed across subtypes.

Several lines of evidence indicate that environmental and maternal characteristics are differentially associated with different subtypes of CP. Some studies have provided evidence that social status ${ }^{323}$ and maternal body weight ${ }^{324}$ are associated with increased risk of hemiplegia, but not other CP subtypes. Consideration of maternal age also influences which factors are most strongly associated with increased risk of different types of $\mathrm{CP}^{306}$. Stratification of infants according to postnatal occurrence of persistent systemic inflammation seems to provide different information about the risk factors associated with quadriplegia ${ }^{299,300}$, but not other CP subtypes, among children who are born before the 28th week of gestation. The CP risk factor profiles for different subtypes among infants with FGR also differ from those for infants with normal growth ${ }^{325}$, especially for children with CP who have FGR and are born at term, among whom rates of congenital birth defects are very high ${ }^{180}$. Some evidence indicates that patterns of childhood growth differ according to CP subtype $^{326}$. Finally, the antecedents of the severest forms of CP seem to differ from those of less severe motor disorders $^{327}$, and in some studies the profile of comorbid neurodevelopmental disorders differs by CP subtype (for example, the co-occurrence of intellectual disability and epilepsy seems to be more likely to develop among children who develop hemiplegia than among children who develop other types of CP $)^{328,329}$.

Despite this evidence, without agreement on reliable definitions of CP subtypes, the findings are difficult to interpret and hard to replicate across populations with different background prevalence of contributing factors. Integration of findings from hypothesis-driven clinical studies and preclinical studies is most likely to inform about the appropriate subdivision of neurodevelopmental syndromes that are rooted in pregnancy.

\section{Future directions}

Large public health interventions (for example, improved access to clean water, hygiene and other interventions that focus on common infections before, during and between pregnancies) combined with rigorous emphasis on hypothesis-driven data collection in LMICs could probably teach us a lot about CP aetiology. A similar focus on periconception modifiable risk factors that influence the early gestation milieu that contributes to increased risk of CP would be informative in LICs and HICs - for example, a focus on alleviating social disadvantage. Overall, there is a pressing need to understand how the environment influences brain development, how it affects placentation and later placental functioning while the brain grows, and why specific environmental factors seem to raise the risk of $\mathrm{CP}$ and precipitating pregnancy disorders.

Current knowledge of the pathogenesis of CP during embryogenesis and placentation rests largely on evidence from models in cell lines and embryos and on downstream placental histopathology and related clinical syndromes ${ }^{330-332}$. However, we do not know whether these methods represent in vivo pathogenesis or how to translate emerging preclinical information into population-level benefits. Maternal and fetal blood-based profiling and imaging techniques are much less informative about pregnancy disorders before the 15 th gestational week ${ }^{333,334}$, which seems to be a key aetiological window ${ }^{333,335-337}$. Emerging technologies, such as trophoblast retrieval and isolation from the cervix $^{338,339}$, might provide relevant information about early placental development and function in ongoing pregnancies, but large follow-up studies are needed to discern the relevance to $\mathrm{CP}$ and its correlates. Single biomarkers are unlikely to be very useful clinically for large sections of the general population, but molecular profiling to establish the timing and order of processes that disrupt physiological homeostasis during pregnancy might prompt better thinking about aetiology and prevention. For example, consideration of key concepts from physiology, such as homeostasis, regulated systems 
and redundancy, as major intellectual tools to understand aetiology might improve our capacity to formulate and test hypotheses ${ }^{340}$ (details of specific examples are available elsewere ${ }^{341-343}$ ).

Infection and other inflammation-inducing exposures before and after very preterm birth are associated with an increased risk of $\mathrm{CP}$ via complex pathways ${ }^{92-94,298,344}$. Some evidence suggests that the risk of CP and comorbid brain disorders is decreased by administration of exogenous proteins that reduce neuroinflammation, possibly by controlling the regulation of systemic inflammation and neuropoietin signalling ${ }^{116,345,346}$; however, meticulously designed, hypothesis-driven preclinical and clinical studies will be needed to translate these observations into population-wide benefits ${ }^{322,347}$.

We cannot overstate the importance of preterm delivery and $\mathrm{FGR}^{348}$, which are themselves heterogeneous syndromes $^{349,350}$, in the $\mathrm{CP}$ risk profile, but large studies of infants born at term, which account for approximately half of all CP diagnoses, might enable easier identification of antecedents, in part because the number of indicators of different pathological processes increases as the gestational age at delivery decreases and, consequently, so does the complexity ${ }^{351-353}$. Population-based studies of pregnancies at all gestational ages will continue to be the most helpful. CP registers and emerging consortiums that focus on standardized data collection, analysis and sharing to study complex pregnancy disorders (for example, CoLab) are beginning to enable the kind of research necessary to examine these possibilities more closely ${ }^{354,355}$.

\section{Conclusions}

We know that the aetiological factors involved in most cases of CP operate between conception and a few weeks after birth, yet identifying preventable causes of $\mathrm{CP}$ has proved difficult. Several risk factors have been identified, but they overlap and interact with each other in ways that are not easy to dissect. Nevertheless, important to keep in mind is that the young 21st century has witnessed the development of two preventive measures for CP: $\mathrm{MgSO}_{4}$ treatment for mothers at risk of preterm delivery, and head and/or body cooling for infants born at term with neonatal encephalopathy.

The ongoing formation of large national databases of data from unselected pregnancies in combination with multidisciplinary collaboration to integrate these resources for the study of complex diseases in pregnancy gives hope for new discoveries; these data include real-time surveys of exposures in pregnant women, and biological specimens such as archived serum, urine and newborn blood spots. This information is invaluable when accompanied by follow-up information about the presence or absence of $\mathrm{CP}$ in the offspring, or when linked to records of CP. If the modest information about pregnancy that is currently available from maternal recall and medical records years later can be supplemented with data sources that provide clear information about exposures to infections, nutrients, environmental toxins, allergens and many other phenomena during pregnancy, our limited knowledge could give way to an era in which the widespread prevention of CP is a feasible goal.

Published online 13 August 2018
1. Kirby, R. S. et al. Prevalence and functioning of children with cerebral palsy in four areas of the United States in 2006: a report from the Autism and Developmental Disabilities Monitoring Network. Res. Dev. Disabil. 32, 462-469 (2011).

2. Christensen, D. et al. Prevalence of cerebral palsy, co-occurring autism spectrum disorders, and motor functioning - Autism and Developmental Disabilities Monitoring Network, USA, 2008. Dev. Med. Child Neurol. 56, 59-65 (2014).

3. Reid, S. M. et al. Temporal trends in cerebral palsy by impairment severity and birth gestation. Dev. Med. Child Neurol 58 (Suppl. 2), 25-35 (2016).

4. Zhang, J. Y., Oskoui, M. \& Shevell, M. A population-based study of communication impairment in cerebral palsy. J. Child Neurol. 30, 277-284 (2015).

5. Mei, C. et al. Language outcomes of children with cerebral palsy aged 5 years and 6 years: a populationbased study. Dev. Med. Child Neurol. 58, 605-611 (2016).

6. Levy, S. E. et al. Autism spectrum disorder and co-occurring developmental, psychiatric, and medical conditions among children in multiple populations of the United States. J. Dev. Behav. Pediatr. 31 267-275 (2010)

7. Pakula, A. T. Van Naarden Braun, K. \& Yeargin-Allsopp, M. Cerebral palsy: classification and epidemiology. Phys. Med. Rehabil. Clin. N. Am. 20, 425-452 (2009)

8. Delobel-Ayoub, M. et al. Prevalence and characteristics of autism spectrum disorders in children with cerebral palsy. Dev. Med. Child Neurol. 59, 738-742 (2017).

9. Kancherla, V., Amendah, D. D., Grosse, S. D., Yeargin-Allsopp, M. \& Van Naarden Braun, K. Medical expenditures attributable to cerebral palsy and intellectual disability among Medicaid-enrolled children. Res. Dev. Disabil. 33, 832-840 (2012).

10. Incidence of infantile cerebral palsy. Acta Poediatr. 46 12-21 (1957)
11. History of the study of cerebralpalsy. Acta Pcediatr. 46, 2-3 (1958).

12. Polani, P. 1. Classification of cerebral palsy: yesterday, and today. Cerebral Palsy Bull. 2, 36-39 (1959).

13. Bax, M. et al. Proposed definition and classification of cerebral palsy, April 2005. Dev. Med. Child Neurol. 47, 571-576 (2005)

14. Rosenbaum, P et al A report: the definition and classification of cerebral palsy April 2006. Dev. Med. Child Neurol. Suppl. 109, 8-14 (2007).

15. Andersen, B. Incidence of cerebral palsy in norway and some C. P. problems. Acta Paediatr. 44, 22-22 (1955).

16. Pharoah, P. O. Epidemiology of cerebral palsy: a review. J. R. Soc. Med. 74, 516-520 (1981)

17. Goldsmith, S. et al. An international survey of cerebral palsy registers and surveillance systems. Dev. Med. Child Neurol 58 (Suppl. 2), 11-17 (2016).

18. Paneth, N. Etiologic factors in cerebral palsy. Pediatr. Ann. 15, 191 (1986)

19. Paneth, N., Hong, T. \& Korzeniewski, S. The descriptive epidemiology of cerebral palsy. Clin. Perinatol, 33, 251-267 (2006)

20. Bhushan, V., Paneth, N. \& Kiely, J. L. Impact of improved survival of very low birth weight infants on recent secular trends in the prevalence of cerebral palsy. Pediatrics 91, 1094-1100 (1993)

21. Yeargin-Allsopp, M. et al. Prevalence of cerebral palsy in 8-year-old children in three areas of the United States in 2002: a multisite collaboration. Pediatrics 121, 547-554 (2008).

22. Arneson, C. L. et al. Prevalence of cerebral palsy: Autism and Developmental Disabilities Monitoring Network, three sites, United States, 2004. Disabil. Health J. 2, 45-48 (2009).

23. Kirby, R. S. et al. Prevalence and functioning of children with cerebral palsy in four areas of the United States in 2006: a report from the Autism and Developmental Disabilities Monitoring Network. Res. Dev. Disabil. 32, 462-469 (2011).

24. Van Naarden Braun, K. et al. Trends in the prevalence of autism spectrum disorder, cerebral palsy, hearing loss, intellectual disability, and vision impairment, metropolitan atlanta, 1991-2010. PLOS One 10 e0124120 (2015).

25. Maenner, M. J. et al. Prevalence of cerebral palsy and intellectual disability among children identified in two U. S. National Surveys, 2011-2013. Ann. Epidemiol. 26, 222-226 (2016).

26. Durkin, M. S. et al. Prevalence of cerebral palsy among 8-year-old children in 2010 and preliminary evidence of trends in its relationship to low birthweight. Paediatr. Perinat. Epidemiol. 30 , 496-510 (2016)

27. Sellier, E et al. Decreasing prevalence in cerebral palsy: a multi-site European population-based study, 1980 to 2003. Dev. Med. Child Neurol. 58, 85-92 (2016).

28. Andersen, G. L. et al. Cerebral palsy among children born moderately preterm or at moderately low birthweight between 1980 and 1998: a European register-based study. Dev. Med. Child Neurol. 53 , 913-919 (2011)

29. Glinianaia, S. V., Rankin, J., Colver, A. \& North of England Collaborative Cerebral Palsy Survey. Cerebral palsy rates by birth weight, gestation and severity in North of England, 1991-2000 singleton births. Arch. Dis. Child 96, 180-185 (2011).

30. Robertson, C. M. T. et al. Prevalence estimate of cerebral palsy in Northern Alberta: births, 2008-2010. Can. J. Neurol. Sci. 44, 366-374 (2017).

31. Hollung, S. J., Vik, T., Lydersen, S., Bakken, I. J. \& Andersen, G. L. Decreasing prevalence and severity of cerebral palsy in Norway among children born 1999 to 2010 concomitant with improvements in perinatal health. Eur. J. Paediatr. Neurol. https://doi. org/10.1016/j.ejpn.2018.05.001 (2018).

32. Touyama, M., Touyama, J., Toyokawa, S. \& Kobayashi, Y. Trends in the prevalence of cerebral palsy in children born between 1988 and 2007 in Okinawa, Japan. Brain Dev. 38, 792-799 (2016).

33. He, P., Chen, G., Wang, Z., Guo, C. \& Zheng, X. Children with motor impairment related to cerebral 
palsy: Prevalence, severity and concurrent impairments in China. J. Paediatr. Child Health 53. 480-484 (2017)

34. Liu, J. M., Li, S., Lin, Q. \& Li, Z. Prevalence of cerebral palsy in China. Int. J. Epidemiol. 28, 949-954 (1999).

35. Toyokawa, S., Maeda, E. \& Kobayashi, Y. Estimation of the number of children with cerebral palsy using nationwide health insurance claims data in Japan Dev. Med. Child Neurol. 59, 317-321 (2017)

36. Park, M. S. et al. Prevalence and lifetime healthcare cost of cerebral palsy in South Korea. Health Policy 100, 234-238 (2011).

37. Gladstone, M. A review of the incidence and prevalence, types and aetiology of childhood cerebral palsy in resource-poor settings. Ann. Trop. Paediatr. 30, 181-196 (2010).

38. Chang, M. J., Ma, H. I. \& Lu, T. H. Estimating the prevalence of cerebral palsy in Taiwan: a comparison of different case definitions. Res. Dev. Disabil. 36C, 207-212 (2014).

39. El-Tallawy, H. N. et al. Cerebral palsy in Al-Quseir City, Egypt: prevalence, subtypes, and risk factors. Neuropsychiatr. Dis. Treat. 10, 1267-1272 (2014).

40. Kakooza-Mwesige, A. et al. Prevalence of cerebral palsy in Uganda: a population-based study. Lancet. Global Health 5, e1275-e1282 (2017).

41. Couper, J. Prevalence of childhood disability in rural KwaZulu-Natal. S. Afr. Med. J. 92, 549-552 (2002).

42. Khandaker, G. et al. Bangladesh Cerebral Palsy Register (BCPR): a pilot study to develop a national cerebral palsy (CP) register with surveillance of children for CP. BMC Neurol. 15, 173 (2015).

43. Delgado, M. R. The Mexican Academy for Cerebral Palsy and Neurodevelopmental Disorders: new kid on the block. Dev. Med. Child Neurol. 58, 109 (2016).

44. Almasri, N. A., Saleh, M., Abu-Dahab, S., Malkawi, S. H. \& Nordmark, E. Development of a cerebral palsy follow-up registry in Jordan (CPUP-Jordan). Child Care Health Dev. 44, 131-139 (2018).

45. Khandaker, G. et al. Protocol for hospital based-surveillance of cerebral palsy (CP) in Hanoi using the Paediatric Active Enhanced Disease Surveillance mechanism (PAEDS-Vietnam): a study towards developing hospital-based disease surveillance in Vietnam. BMJ Open 7, e017742 (2017).

46. Little, W. J. The classic: hospital for the cure of deformities: course of lectures on the deformities of the human frame. 1843. Clin. Orthop. Relat. Res. 470, 1252-1256 (2012).

47. Little, W. J. in Transactions of the Obstetrical Society of London. 293-344 (Longmans, Green and Co, 1862)

48. Freud, S. Die Infantilen Cerebrallahmungen (KuK Hoflieferant, 1897).

49. Evans, P. R. Antecedents of infantile cerebral palsy. Arch. Dis. Child 23, 213-219 (1948).

50. Freud, S. Infantile cerebral paralysis (Univ. of Miami Press, 1968)

51. Dan, B., Rosenbloom, L. \& Paneth, N. Cerebral palsy (Mac Keith Press, 2014)

52. Yannet, $\mathrm{H}$. The etiology of congenital cerebral palsy. J. Pediatr. 24, 38-45 (1944).

53. Nelson, K. B. \& Ellenberg, J. H. Antecedents of cerebral palsy. Multivariate analysis of risk. N. Engl. J. Med. 315, 81-86 (1986).

54. Paneth, N. \& Fox, H. E. The relationship of Apgar score to neurologic handicap: a survey of clinicians. Obstet. Gynecol. 61, 547-550 (1983).

55. Paneth, N. \& Stark, R. I. Cerebral palsy and mental retardation in relation to indicators of perinatal asphyxia. An epidemiologic overview. Am. J. Obstet. Gynecol. 147, 960-966 (1983).

56. Badawi, N. et al. Cerebral palsy following term newborn encephalopathy: a population-based study. Dev. Med. Child Neurol. 47, 293-298 (2005).

57. Badawi, N. et al. Intrapartum risk factors for newborn encephalopathy: the Western Australian case-control study. BMJ 317, 1554-1558 (1998)

58. Ellenberg, J. H. \& Nelson, K. B. The association of cerebral palsy with birth asphyxia: a definitional quagmire. Dev. Med. Child Neurol. 55, 210-216 (2013).

59. Nelson, K. B., Sartwelle, T. P. \& Rouse, D. J. Electronic fetal monitoring, cerebral palsy, and caesarean section: assumptions versus evidence. BMJ 355 , i6405 (2016).

60. Salafia, C. M., Mangam, H. E., Weigl, C. A., Foye, G. J. $\&$ Silberman, L. Abnormal fetal heart rate patterns and placental inflammation. Am. J. Obstet. Gynecol. 160, 140-147 (1989).
61. Rouse, D. J. et al. The Maternal-Fetal Medicine Units cesarean registry: chorioamnionitis at term and its duration-relationship to outcomes. Am. J. Obstet. Gynecol. 191, 211-216 (2004).

62. O'Callaghan, M. et al. Epidemiologic associations with cerebral palsy. Obstet. Gynecol. 118, 576-582 (2011).

63. Vissenberg, R. et al. Abnormal thyroid function parameters in the second trimester of pregnancy are associated with breech presentation at term: a nested cohort study. Eur. J. Obstet. Gynecol. Reprod. Biol. 199, 169-174 (2016).

64. Macharey, G. et al. Breech presentation at term and associated obstetric risks factors-a nationwide population based cohort study. Arch. Gynecol. Obstet. 295, 833-838 (2017).

65. Hofmeyr, G. J. \& Hannah, M. E. Planned caesarean section for term breech delivery. Cochrane Database Syst. Rev. 7, CD000166 (2003).

66. Himmelmann, K., Hagberg, G. \& Uvebrant, P. The changing panorama of cerebral palsy in Sweden. $X$. Prevalence and origin in the birth-year period 1999-2002. Acta Paediatr. 99, 1337-1343 (2010).

67. Schieve, L. A. et al. Population impact of preterm birth and low birth weight on developmental disabilities in US children. Ann. Epidemiol. 26, 267-274 (2016).

68. Dammann, O. \& Leviton, A. Perinatal brain damage causation. Dev. Neurosci. 29, 280-288 (2007)

69. Tran, U., Gray, P. H. \& O'Callaghan, M. J. Neonatal antecedents for cerebral palsy in extremely preterm babies and interaction with maternal factors. Early Hum. Dev. 81, 555-561 (2005)

70. Pinto-Martin, J. A. et al. Cranial ultrasound prediction of disabling and nondisabling cerebral palsy at age two in a low birth weight population. Pediatrics 95 249-254 (1995)

71. Skovgaard, A. L. \& Zachariassen, G. Cranial ultrasound findings in preterm infants predict the development of cerebral palsy. Dan. Med. J. 64, A5330 (2017).

72. Reubsaet, P. et al. The impact of low-grade germinal matrix-intraventricular hemorrhage on neurodevelopmental outcome of very preterm infants. Neonatology 112, 203-210 (2017).

73. Radic, J. A., Vincer, M. \& McNeely, P. D. Outcomes of intraventricular hemorrhage and posthemorrhagic hydrocephalus in a population-based cohort of very preterm infants born to residents of Nova Scotia from 1993 to 2010. J. Neurosurg. Pediatr. 15, 580-588 (2015).

74. Mukerji, A., Shah, V. \& Shah, P. S. Periventricular intraventricular hemorrhage and neurodevelopmental outcomes: a meta-analysis. Pediatrics 136 1132-1143 (2015)

75. Sola-Visner, M. Prognostic significance of low-grade intraventricular hemorrhage in the current era of neonatology. JAMA Pediatr, 1-2 (2013).

76. Bolisetty, S. et al. Intraventricular hemorrhage and neurodevelopmental outcomes in extreme preterm infants. Pediatrics 133, 55-62 (2014).

77. Tsai, W. H. et al. Association between mechanical ventilation and neurodevelopmental disorders in a nationwide cohort of extremely low birth weight infants. Res. Dev. Disabil. 35, 1544-1550 (2014).

78. Bosco, J. L. et al. A most stubborn bias: no adjustment method fully resolves confounding by indication in observational studies. J. Clin. Epidemiol. 63, 64-74 (2010)

79. Murase, M. \& Ishida, A. Early hypocarbia of preterm infants: its relationship to periventricular leukomalacia and cerebral palsy, and its perinatal risk factors. Acta Paediatr. 94, 85-91 (2005).

80. Graziani, L. J. et al. Mechanical ventilation in preterm infants: neurosonographic and developmental studies. Pediatrics 90, 515-522 (1992).

81. Leviton, A. et al. Early blood gas abnormalities and the preterm brain. Am. J. Epidemiol. 172, 907-916 (2010).

82. Okumura, A. et al. Hypocarbia in preterm infants with periventricular leukomalacia: the relation between hypocarbia and mechanical ventilation. Pediatrics 107, 469-475 (2001).

83. Wiswell, T. E. et al. High-frequency jet ventilation in the early management of respiratory distress syndrome is associated with a greater risk for adverse outcomes. Pediatrics 98, 1035-1043 (1996).

84. Giannakopoulou, C. et al. Significance of hypocarbia in the development of periventricular leukomalacia in preterm infants. Pediatr. Int. 46, 268-273 (2004).

85. Greisen, G. $\&$ Borch, K. White matter injury in the preterm neonate: the role of perfusion. Dev. Neurosci. 23, 209-212 (2001)
86. Greisen, G. \& Vannucci, R. C. Is periventricular leucomalacia a result of hypoxic-ischaemic injury? Hypocapnia and the preterm brain. Biol. Neonate 79, 194-200 (2001)

87. Volpe, J. J. Neurobiology of periventricular leukomalacia in the premature infant. Pediatr. Res. 50, 553-562 (2001)

88. Collins, M. P., Lorenz, J. M., Jetton, J. R. \& Paneth, N Hypocapnia and other ventilation-related risk factors for cerebral palsy in low birth weight infants. Pediatr. Res. 50, 712-719 (2001).

89. Chawla, S. et al. Association of neurodevelopmenta outcomes and neonatal morbidities of extremely premature infants with differential exposure to antenatal steroids. JAMA Pediatr. 170, 1164-1172 (2016).

90. Halliday, H. L., Ehrenkranz, R. A. \& Doyle, L. W. Late ( $>7$ days) postnatal corticosteroids for chronic lung disease in preterm infants. Cochrane Database Syst. Rev. 10, CD001145 (2009).

91. Linsell, L., Malouf, R., Morris, J., Kurinczuk, J. J. \& Marlow, N. Prognostic factors for cerebral palsy and motor impairment in children born very preterm or very low birthweight: a systematic review. Dev. Med. Child Neurol. 58, 554-569 (2016).

92. Kuban, K. C. et al. Systemic inflammation and cerebral palsy risk in extremely preterm infants. J. Child Neurol. 29, 1692-1698 (2014).

93. Kuban, K. C. et al. The breadth and type of systemic inflammation and the risk of adverse neurological outcomes in extremely low gestation newborns. Pediatr. Neurol. 52, 42-48 (2015).

94. Carlo, W. A. et al. Cytokines and neurodevelopmental outcomes in extremely low birth weight infants. J. Pediatr. 159, 919-925.e3 (2011).

95. La Gamma, E. F., Korzeniewski, S. J., Ballabh, P. \& Paneth, N. Transient Hypothyroxinemia of Prematurity. NeoReviews 17, e394-e402 (2016).

96. Shih, J. L. ¿ Agus, M. S. Thyroid function in the critically ill newborn and child. Curr. Opin. Pediatr. 21 536-540 (2009).

97. Kaluarachchi, D. C., Colaizy, T. T., Pesce, L. M. Tansey, M. \& Klein, J. M. Congenital hypothyroidism with delayed thyroid-stimulating hormone elevation in premature infants born at less than 30 weeks gestation. J. Perinatol. 37, 277-282 (2017).

98. Cavarzere, P. et al. Congenital hypothyroidism with delayed TSH elevation in low-birth-weight infants: incidence, diagnosis and management. Eur. J. Endocrinol. 175, 395-402 (2016).

99. Silva, M. H., Araujo, M. C., Diniz, E. M., Ceccon, M. E. $\&$ Carvalho, W. B. Nonthyroidal illnesses syndrome in full-term newborns with sepsis. Arch. Endocrinol. Metab. 59, 528-534 (2015).

100. Marks, S. D. Nonthyroidal illness syndrome in children. Endocrine 36, 355-367 (2009)

101. De Groot, L. J. Dangerous dogmas in medicine: the nonthyroidal illness syndrome. J. Clin. Endocrinol. Metab. 84, 151-164 (1999).

102. Mclver, B. \& Gorman, C. A. Euthyroid sick syndrome: an overview. Thyroid 7, 125-132 (1997).

103. Chowdhry, P., Auerbach, R., Scanlon, J. \& Abbassi, V. The nature of hypothyroxinemia in sick preterm infants. Pediatr. Res. 15, 505-505 (1981).

104. Diamond, F. B., Parks, J. S., Tenore, A., Marino, J. M. $\&$ Bongiovanni, A. M. Hypothyroxinemia in sick and well preterm infants. Clin. Pediatr. 18, 559-561 (1979).

105. Cuestas, R. A., Lindall, A. \& Engel, R. R. Low thyroid hormones and respiratory-distress syndrome of the newborn. Studies on cord blood. N. Engl. J. Med. 295 297-302 (1976).

106. Ares, S., Quero, J., Diez, J. \& Morreale de Escobar, C. Neurodevelopment of preterm infants born at 28 to 36 weeks of gestational age: the role of hypothyroxinemia and long-term outcome at 4 years. J. Pediatr. Endocrinol. Metab. 24, 897-902 (2011).

107. Hollanders, J. J. et al. Transient hypothyroxinemia of prematurity and problem behavior in young adulthood. Psychoneuroendocrinology 72, 40-46 (2016).

108. Den Ouden, A. L., Kok, J. H., Verkerk, P. H., Brand, R. $\&$ Verloove-Vanhorick, S. P. The relation between neonatal thyroxine levels and neurodevelopmental outcome at age 5 and 9 years in a national cohort of very preterm and/or very low birth weight infants. Pediatr. Res. 39, 142-145 (1996).

109. Meijer, W. J., Verloovevanhorick, S. P., Brand, R. \& Vandenbrande, J. L. Transient hypothyroxinemia associated with developmental delay in very preterm infants. Arch. Dis. Childhood 67, 944-947 (1992). 
110. Reuss, M. L., Paneth, N., Pinto-Martin, J. A. Lorenz, J. M. \& Susser, M. The relation of transient hypothyroxinemia in preterm infants to neurologic development at two years of age. N. Engl. J. Med. 334, 821-827 (1996).

111. Hollanders, J. J. et al. No association between transient hypothyroxinemia of prematurity and neurodevelopmental outcome in young adulthood. J. Clin. Endocrinol. Metab. 100, 4648-4653 (2015).

112. Trumpff, C. et al. Thyroid-stimulating hormone (TSH) concentration at birth in belgian neonates and cognitive development at preschool age. Nutrients 7. 9018-9032 (2015)

113. DenOuden, A. L., Kok, J. H., Verkerk, P. H., Brand, R. $\&$ VerlooveVanhorick, S. P. The relation between neonatal thyroxine levels and neurodevelopmental outcome at age 5 and 9 years in a national cohort of very preterm and/or very low birth weight infants. Pediatr. Res. 39, 142-145 (1996).

114. Leviton, A. et al. Hypothyroxinemia of prematurity and the risk of cerebral white matter damage. J. Pediatr. 134, 706-711 (1999).

115. La Gamma, E. F. et al. Phase 1 trial of 4 thyroid hormone regimens for transient hypothyroxinemia in neonates of $<28$ weeks' gestation. Pediatrics 124 , e258-268 (2009)

116. Hong, T. \& Paneth, N. Maternal and infant thyroid disorders and cerebral palsy. Semin. Perinatol. 32 438-445 (2008)

117. Rogan, W. J. et al. lodine deficiency, pollutant chemicals, and the thyroid: new information on an old problem. Pediatrics 133, 1163-1166 (2014).

118. O'Callaghan, M. E. et al. Epidemiologic associations with cerebral palsy. Obstet. Gynecol. 118, 576-582 (2011)

119. Hemminki, K , Li, X Sundquist, K. \& Sundquist, J. High familial risks for cerebral palsy implicate partial heritable aetiology. Paediatr. Perinat. Epidemiol. 21 235-241 (2007).

120. Tollanes, M. C., Wilcox, A. J., Lie, R. T. \& Moster, D. Familial risk of cerebral palsy: population based cohort study. BMJ 349, g4294 (2014).

121. Fahey, M. C., Maclennan, A. H., Kretzschmar, D., Gecz, J. \& Kruer, M. C. The genetic basis of cerebra palsy. Dev. Med. Child Neurol. 59, 462-469 (2017).

122. McMichael, G. et al. Whole-exome sequencing points to considerable genetic heterogeneity of cerebral palsy. Mol. Psychiatry 20, 176-182 (2015).

123. Meirelles Kalil Pessoa de, B., Rodrigues, C. J., de Barros, T. E. \& Bevilacqua, R. G. Presence of apolipoprotein $\mathrm{E} \varepsilon 4$ allele in cerebral palsy. J. Pediatr. Orthop. 20, 786-789 (2000).

124. Kuroda, M. M., Weck, M. E., Sarwark, J. F., Hamidullah, A. \& Wainwright, M. S. Association of apolipoprotein E genotype and cerebral palsy in children. Pediatrics 119, 306-313 (2007).

125. Wu, Y. W., Croen, L. A., Vanderwerf, A., Gelfand, A. A. $\&$ Torres, A. R. Candidate genes and risk for CP: a population-based study. Pediatr. Res. 70, 642-646 (2011)

126. Lien, E et al. Apolipoprotein E polymorphisms and severity of cerebral palsy: a cross-sectional study in 255 children in Norway. Dev. Med. Child Neurol. 55, 372-377 (2013)

127. Lien, E. et al. Genes determining the severity of cerebral palsy: the role of single nucleotide polymorphisms on the amount and structure of apolipoprotein E. Acta Paediatr. 104, 701-706 (2015).

128. Braga, L. W. et al. Apolipoprotein E genotype and cerebral palsy. Dev. Med. Child Neurol. 52, 666-671 (2010).

129. Stoknes, M. et al. Child apolipoprotein E gene variants and risk of cerebral palsy: estimation from case-parent triads. Eur. J. Paediatr. Neurol. 19, 286-291 (2015).

130. McMichael, G. L. et al. Association between Apolipoprotein E genotype and cerebral palsy is not confirmed in a Caucasian population. Hum. Genet. 124, 411-416 (2008).

131. O'Callaghan, M. E. et al. Fetal and maternal candidate single nucleotide polymorphism associations with cerebral palsy: a case-control study. Pediatrics 129 e414-e423 (2012).

132. Xu, Y. et al. The association of apolipoprotein $E$ gene polymorphisms with cerebral palsy in Chinese infants. Mol. Genet. Genomics 289, 411-416 (2014).

133. O'Callaghan, M. E., MacLennan, A. H., Haan, E. A., Dekker, G. ¿ South Australian Cerebral Palsy Research Group. The genomic basis of cerebral palsy: a HuGE systematic literature review. Hum. Genet. 126 , 149-172 (2009)
134. Vohr, B. R. et al. Maternal age, multiple birth, and extremely low birth weight infants. J. Pediatr. 154 498-503.e2 (2009).

135. Luu, T. M. \& Vohr, B. Twinning on the brain: the effect on neurodevelopmental outcomes. Am. J. Med. Genet C Semin. Med. Genet. 151 C, 142-147 (2009).

136. Yokoyama, Y., Shimizu, T. \& Hayakawa, K. Prevalence of cerebral palsy in twins, triplets and quadruplets. Int. J. Epidemiol. 24, 943-948 (1995).

137. Pharoah, P. O. \& Cooke, T. Cerebral palsy and multiple births. Arch. Dis. Child Fetal Neonatal Ed. 75, F174-F177 (1996).

138. Topp, M. et al. Multiple birth and cerebral palsy in Europe: a multicenter study. Acta Obstet. Gynecol. Scand. 83, 548-553 (2004).

139. Maenner, M. J. et al. Children with cerebral palsy: racial disparities in functional limitations. Epidemiology 23, 35-43 (2012).

140. Wu, Y. W. et al. Racial, ethnic, and socioeconomic disparities in the prevalence of cerebral palsy. Pediatrics 127, e674-e681 (2011).

141. Petterson, B., Nelson, K. B., Watson, L. \& Stanley, F Twins, triplets, and cerebral palsy in births in Western Australia in the 1980s. BMJ 307, 1239-1243 (1993).

142. Lorenz, J. M. Neurodevelopmental outcomes of twins. Semin. Perinatol 36, 201-212 (2012).

143. Scher, A. I. et al. The risk of mortality or cerebral palsy in twins: a collaborative population-based study. Pediatr. Res. 52, 671-681 (2002).

144. Petterson, B., Stanley, F. \& Henderson, D. Cerebral palsy in multiple births in Western Australia: genetic aspects. Am. J. Med. Genet. 37, 346-351 (1990).

145. Steingass, K. J., Taylor, H. G., Wilson-Costello, D., Minich, N. \& Hack, M. Discordance in neonatal risk factors and early childhood outcomes of very low birth weight $(<1.5 \mathrm{~kg})$ twins. J. Perinatol. 33, 388-393 (2013).

146. Hack, K. E. et al. Long-term neurodevelopmental outcome of monochorionic and matched dichorionic twins. PLOS One 4, e6815 (2009).

147. Swamy, R. S. et al. Cognitive outcome in childhood of birth weight discordant monochorionic twins: the long-term effects of fetal growth restriction. Arch. Dis. Child Fetal Neonatal Ed. https://doi.org/ 10.1136/archdischild-2017-313691 (2018).

148. Halling, C. \& Corcoran, J. D. Little and large: the effects of twin growth discordance. Arch. Dis. Child Fetal Neonatal Ed. https://doi.org/10.1136/ archdischild-2017-314572 (2018).

149. Pharoah, P. O. \& Dundar, Y. Monozygotic twinning, cerebral palsy and congenital anomalies. Hum. Reprod. Update 15, 639-648 (2009).

150. Glinianaia, S. V., Rankin, J. \& Wright, C. Congenital anomalies in twins: a register-based study. Hum. Reprod. 23, 1306-1311 (2008).

151. Pharoah, P. O.\& Cooke, R. W. A hypothesis for the aetiology of spastic cerebral palsy - the vanishing twin. Dev. Med. Child Neurol. 39, 292-296 (1997).

152. Grether, J. K., Nelson, K. B. \& Cummins, S. K. Twinning and cerebral palsy: experience in four northern California counties, births 1983 through 1985. Pediatrics 92, 854-858 (1993)

153. Solaski, M., Majnemer, A. \& Oskoui, M. Contribution of socio-economic status on the prevalence of cerebral palsy: a systematic search and review. Dev. Med. Child Neurol. 56, 1043-1051 (2014).

154. Oskoui, M., Messerlian, C., Blair, A., Gamache, P. \& Shevell, M. Variation in cerebral palsy profile by socio-economic status. Dev. Med. Child Neurol. $\mathbf{5 8}$ 160-166 (2016)

155. Dolk, $\mathrm{H}$. et al. Socio-economic inequalities in cerebral palsy prevalence in the United Kingdom: a register-based study. Paediatr. Perinat. Epidemiol. 24, 149-155 (2010).

156. Hjern, A. \& Thorngren-Jerneck, K. Perinatal complications and socio-economic differences in cerebral palsy in Sweden - a national cohort study. BMC Pediatr. 8, 49 (2008).

157. Tseng, S. H., Lee, J. Y., Chou, Y. L., Sheu, M. L. \& Lee, Y. W. Association between socioeconomic status and cerebral palsy. PLOS One 13, e0191724 (2018).

158. Heslehurst, N. et al. Trends in maternal obesity incidence rates, demographic predictors, and health inequalities in 36,821 women over a 15-year period. BJOG 114, 187-194 (2007).

159. Micklesfield, L. K. et al. Socio-cultural, environmental and behavioural determinants of obesity in black South African women. Cardiovascular J. Afr. 24, 369-375 (2013).

160. Sommer, C. et al. Ethnic differences in maternal dietary patterns are largely explained by socio-economic score and integration score: a population-based study. Food Nutr. Res. $\mathbf{5 7}$ 21164 (2013).

161. Mohsena, M., Goto, R. \& Mascie-Taylor, C. N Maternal nutritional status (as measured by height, weight and $\mathrm{BMI}$ ) in Bangladesh: trends and socio-economic association over the period 1996 to 2007. Publ. Health Nutr. 19, 1438-1445 (2016).

162. Crisham Janik, M. D. et al. Maternal diagnosis of obesity and risk of cerebral palsy in the child. J. Pediatr. 163, 1307-1312 (2013).

163. Pan, C., Deroche, C. B., Mann, J. R., McDermott, S. \& Hardin, J. W. Is prepregnancy obesity associated with risk of cerebral palsy and epilepsy in children? J. Child Neurol. 29, NP196-NP201 (2014).

164. Forthun, I. et al. Maternal prepregnancy BMI and risk of cerebral palsy in offspring. Pediatrics 138 e20160874 (2016).

165. Zhu, M. J., Du, M. ¿ Ford, S. P. Cell Biology Symposium: impacts of maternal obesity on placental and gut inflammation and health. J. Anim. Sci. 92, 1840-1849 (2014)

166. Huang, L. et al. Maternal prepregnancy obesity is associated with higher risk of placental pathological lesions. Placenta 35, 563-569 (2014).

167. Bronson, S. L. \& Bale, T. L. The placenta as a mediator of stress effects on neurodevelopmental reprogramming. Neuropsychopharmacology 41, 207-218 (2016)

168. Myatt, L. \& Maloyan, A. Obesity and placental function. Semin. Reprod. Med. 34, 42-49 (2016).

169. Mannisto, T. et al. Early pregnancy reference intervals of thyroid hormone concentrations in a thyroid antibody-negative pregnant population. Thyroid 21, 291-298 (2011)

170. Mosso, L. et al. Early pregnancy thyroid hormone reference ranges in Chilean women: the influence of body mass index. Clin. Endocrinol. 85, 942-948 (2016).

171. van der Burg, J. W. et al. Are extremely low gestational age newborns born to obese women at increased risk of cerebral palsy at 2 years? J. Child Neurol. 33, 216-224 (2018).

172. Ozturk, A. et al. Antenatal and delivery risk factors and prevalence of cerebral palsy in Duzce (Turkey). Brain Dev. 29, 39-42 (2007).

173. Thorngren-Jerneck, K. \& Herbst, A. Perinatal factors associated with cerebral palsy in children born in Sweden. Obstet. Gynecol. 108, 1499-1505 (2006).

174. Zhao, M., Dai, H., Deng, Y. \& Zhao, L. SGA as a risk factor for cerebral palsy in moderate to late preterm infants: a system review and meta-analysis. Sci. Rep. 6, 38853 (2016)

175. Blair, E., Watson, L. \& Australian Cerebral Palsy Register Group. Cerebral palsy and perinatal mortality after pregnancy-induced hypertension across the gestational age spectrum: observations of a reconstructed total population cohort. Dev. Med. Child Neurol. 58 (Suppl. 2), 76-81 (2016).

176. Jarvis, S. et al. Cerebral palsy and intrauterine growth in single births: European collaborative study. Lancet 362, 1106-1111 (2003).

177. Grether, J. K., Nelson, K. B., Emery, E. S. 3rd \& Cummins, S. K. Prenatal and perinatal factors and cerebral palsy in very low birth weight infants. J. Pediatr. 128, 407-414 (1996).

178. Xiong, X., Saunders, L. D., Wang, F. L., Davidge, S. T. \& Buekens, P. Preeclampsia and cerebral palsy in low-birth-weight and preterm infants: implications for the current "ischemic model" of preeclampsia. Hypertens. Pregnancy 20, 1-13 (2001).

179. Arnold, C. C., Kramer, M. S., Hobbs, C. A., Mclean, F. H. \& Usher, R. H. Very low birth weight - a problematic cohort for epidemiologic studies of very small or immature neonates. Am. J. Epidemiol. 134, 604-613 (1991).

180. Blair, E. M. \& Nelson, K. B. Fetal growth restriction and risk of cerebral palsy in singletons born after at least 35 weeks' gestation. Am. J. Obstet. Gynecol. 212, 520.e1-520.e7 (2015).

181. Blair, E. The undesirable consequences of controlling for birth weight in perinatal epidemiological studies. $J$ Epidemiol Commun. Health 50, 559-563 (1996).

182. Kramer, M. S. Gestational age, birthweight, and their influence on neonatal outcome. Acta Paediatr. 104, 5-6 (2015).

183. O'Shea, T. M. et al. The ELGAN study of the brain and related disorders in extremely low gestational age newborns. Early Hum. Dev. 85, 719-725 (2009).

184. Tsimis, M. E. et al. Risk factors for periventricular white matter injury in very low birthweight neonates. Am. J. Obstet. Gynecol. 214, 380.e1-380.e6 (2016). 
185. Leviton, A. et al. Microbiologic and histologic characteristics of the extremely preterm infant's placenta predict white matter damage and later cerebral palsy. the ELGAN study. Pediatr. Res. 67 95-101 (2010)

186. Dammann, O. Persistent neuro-inflammation in cerebral palsy: a therapeutic window of opportunity? Acta Paediatr. 96, 6-7 (2007).

187. Dammann, O. Causality, mosaics, and the health sciences. Theor. Med. Bioeth. 37, 161-168 (2016).

188. Dammann, O. \& Leviton, A. Inflammatory brain damage in preterm newborns-dry numbers, wet lab, and causal inferences. Early Hum. Dev. 79, 1-15 (2004).

189. Schendel, D. E. Infection in pregnancy and cerebral palsy. Journal of the American Medical Women's Association 56, 105-108 (2001) (1972).

190. Smithers-Sheedy, H. et al. Congenital cytomegalovirus among children with cerebral palsy. J. Pediatr. 181, 267-271 (2017)

191. Smithers-Sheedy, H. et al. Congenital cytomegalovirus is associated with severe forms of cerebral palsy and female sex in a retrospective population-based study. Dev. Med. Child Neurol. 56, 846-852 (2014).

192. Gerardin, P. et al. Neurocognitive outcome of children exposed to perinatal mother-to-child Chikungunya virus infection: the CHIMERE cohort study on Reunion Island. PLoS Negl. Trop. Dis. 8, e2996 (2014).

193. Meneses, J. D. A. et al. Lessons learned at the epicenter of Brazil's congenital zika epidemic: evidence from 87 confirmed cases. Clin. Infect. Dis. 64, 1302-1308 (2017)

194. Pessoa, A. et al. Motor abnormalities and epilepsy in infants and children with evidence of congenital Zika virus infection. Pediatrics 141, S167-S179 (2018)

195. Streja, E. et al. Congenital cerebral palsy and prenatal exposure to self-reported maternal infections, fever, or smoking. Am. J. Obstet. Gynecol. 209, 332.e1-332. e10 (2013)

196. Abdullahi, H., Satti, M., Rayis, D. A., Imam, A. M. \& Adam, I. Intra-partum fever and cerebral palsy in Khartoum, Sudan. BMC Res. Notes 6, 163 (2013).

197. Wu, Y. W. \& Colford, J. M. Chorioamnionitis as a risk factor for cerebral palsy - a meta-analysis. JAMA 284 1417-1424 (2000)

198. Meeraus, W. H., Petersen, I. \& Gilbert, R. Association between antibiotic prescribing in pregnancy and cerebral palsy or epilepsy in children born at term a cohort study using the health improvement network. PLOS One 10, e0122034 (2015).

199. Wu, Y. W. et al. Chorioamnionitis and cerebral palsy in term and near-term infants. JAMA 290, 2677-2684 (2003).

200. Wu, Y. W. Systematic review of chorioamnionitis and cerebral palsy. Mental Retard. Dev. Disabilities Res. Rev. 8, 25-29 (2002).

201. Bear, J. J. \& Wu, Y. W. Maternal infections during pregnancy and cerebral palsy in the child. Pediatr. Neurol. 57, 74-79 (2016).

202. Miller, J. E. et al. Maternal infections during pregnancy and cerebral palsy: a population-based cohort study. Paediatr. Perinat. Epidemiol. 27, 542-552 (2013)

203. Polivka, B. J., Nickel, J. T. \& Wilkins, J. R. 3rd. Urinary tract infection during pregnancy: a risk factor for cerebral palsy? J. Obstet. Gynecol. Neonatal Nurs. 26, 405-413 (1997).

204. O'Shea, T. M., Klinepeter, K. L., Meis, P. J. \& Dillard, R. G. Intrauterine infection and the risk of cerebral palsy in very low-birthweight infants. Paediatr. Perinat. Epidemiol. 12, 72-83 (1998).

205. Brookfield, K. F., Osmundson, S. S., Caughey, A. B. \& Snowden, J. M. Does infection during pregnancy outside of the time of delivery increase the risk of cerebral palsy? Am. J. Perinatol. 34, 223-228 (2017).

206. Korzeniewski, S. J., Birbeck, G., DeLano, M. C. Potchen, M. J. \& Paneth, N. A. Systematic review of neuroimaging for cerebral palsy. J. Child Neurol. 23 216-227 (2008)

207. Tsutsui, Y., Nagahama, M. \& Mizutani, A. Neuronal migration disorders in cerebral palsy. Neuropathology 19, 14-27 (1999).

208. Kulak, W. et al. Schizencephaly as a cause of spastic cerebral palsy. Adv. Med. Sci. 56, 64-70 (2011).

209. Clark, M., Carr, L., Reilly, S. \& Neville, B. G. Worster-Drought syndrome, a mild tetraplegic perisylvian cerebral palsy. Review of 47 cases. Brain 123, 2160-2170 (2000)

210. Bosnjak, V. M. et al. Malformations of cortical development in children with congenital cytomegalovirus infection - A study of nine children with proven congenital cytomegalovirus infection Coll. Antropol. 35 (Suppl. 1), 229-234 (2011).

211. Edebol-Tysk, K. Epidemiology of spastic tetraplegic cerebral palsy in Sweden. I. Impairments and disabilities. Neuropediatrics 20, 41-45 (1989)

212. Contreras-Capetillo, S. N. et al. Birth defects associated with congenital zika virus infection in mexico. Clin. Pediatr. 57, 927-936 (2017).

213. Zheng, X. Y. et al. Intrauterine infections and birth defects. Biomed. Environ. Sci. 17, 476-491 (2004).

214. Mclntyre, S., Blair, E., Badawi, N., Keogh, J. \& Nelson, K. B. Antecedents of cerebral palsy and perinatal death in term and late preterm singletons. Obstet. Gynecol. 122, 869-877 (2013).

215. Pharoah, P. O. Prevalence and pathogenesis of congenital anomalies in cerebral palsy. Arch. Dis. Child Fetal Neonatal Ed. 92, F489-F493 (2007).

216. Rankin, J. et al. Congenital anomalies in children with cerebral palsy: a population-based record linkage study. Dev. Med. Child Neurol. 52, 345-351 (2010)

217. Nattel, S. N. et al. Congenital heart disease and neurodevelopment: clinical manifestations, genetics, mechanisms, and implications. Can. J. Cardiol. 33, 1543-1555 (2017).

218. Bellizzi, S. et al. Are hypertensive disorders in pregnancy associated with congenital malformations in offspring? Evidence from the WHO Multicountry cross sectional survey on maternal and newborn health. BMC Pregnancy Childbirth 16, 198 (2016).

219. Howley, M. M. et al. Thyroid medication use and birth defects in the National Birth Defects Prevention Study. Birth Defects Res. 109, 1471-1481 (2017).

220. Hashmi, S. S. et al. The association between neonatal thyroxine and craniosynostosis, Texas, 2004-2007. Birth Defects Res. A Clin. Mol. Teratol. 94 1004-1009 (2012).

221. Stoll, C., Dott, B., Alembik, Y. \& Koehl, C. Congenital anomalies associated with congenital hypothyroidism. Ann. Genet. 42, 17-20 (1999).

222. Pei, L. \& Wallace, D. C. Mitochondrial etiology of neuropsychiatric disorders. Biol. Psychiatry 83 , 722-730 (2017).

223. Wu, Y. W. et al. Perinatal stroke in children with motor impairment: a population-based study. Pediatrics 114 612-619 (2004)

224. Uvebrant, P. Hemiplegic cerebral palsy. Aetiology and outcome. Acta Paediatr. Scand. Suppl. 345, 1-100 (1988).

225. Wu, Y. W., Croen, L. A., Shah, S. J., Newman, T. B. \& Najjar, D. V. Cerebral palsy in a term population: risk factors and neuroimaging findings. Pediatrics 118 690-697 (2006)

226. Kirton, A., Deveber, G., Pontigon, A. M., Macgregor, D. $\&$ Shroff, M. Presumed perinatal ischemic stroke: vascular classification predicts outcomes. Ann. Neurol. 63, 436-443 (2008)

227. Cole, L. et al. Clinical characteristics, risk factors, and outcomes associated with neonatal hemorrhagic stroke: a population-based case-control study. JAMA Pediatr. 171, 230-238 (2017).

228. Kirton, A. et al. Symptomatic neonatal arterial ischemic stroke: the International Pediatric Stroke Study. Pediatrics 128, e1402-1410 (2011).

229. Fitzgerald, K. C. \& Golomb, M. R. Neonatal arterial ischemic stroke and sinovenous thrombosis associate with meningitis. J. Child Neurol. 22, 818-822 (2007).

230. Lee, J. et al. Maternal and infant characteristics associated with perinatal arterial stroke in the infant. JAMA 293, 723-729 (2005).

231. Kraus, F. T. \& Acheen, V. I. Fetal thrombotic vasculopathy in the placenta: cerebral thrombi and infarcts, coagulopathies, and cerebral palsy. Hum. Pathol. 30, 759-769 (1999).

232. Bhutani, V. K., Vilms, R. J. \& Hamerman-Johnson, L. Universal bilirubin screening for severe neonatal hyperbilirubinemia. J. Perinatol. 30 (Suppl.), S6-S15 (2010).

233. Brites, D. \& Bhutani, V. Pathways involving bilirubin and other brain-injuring agents in Cerebral Palsy: Science and Clinical Practice 131-150 (Mac Ke3ith Press, 2014)

234. Asher, P. \& Schonell, F. E. Cerebral palsy. Lancet 257 1201-1201 (1949).

235. Asher, P. \& Schonell, F. E. A survey of 400 cases of cerebral palsy in childhood. Arch. Dis. Child 25 360-379 (1950)

236. Bhutani, V. K. et al. Neonatal hyperbilirubinemia and Rhesus disease of the newborn: incidence and impairment estimates for 2010 at regional and global levels. Pediatr. Res. 74 (Suppl. 1), 86-100 (2013).

237. Olusanya, B. O. \& Slusher, T. M. Infants at risk of significant hyperbilirubinemia in poorly-resourced countries: evidence from a scoping review. World J. Pediatrics 11, 293-299 (2015).

238. Kuban, K. C. et al. Maternal toxemia is associated with reduced incidence of germinal matrix hemorrhage in premature babies. J. Child Neurol. 7, 70-76 (1992).

239. Nelson, K. B. \& Grether, J. K. Can magnesium sulfate reduce the risk of cerebral palsy in very low birthweight infants. Pediatrics 95, 263-269 (1995).

240. Schendel, D. E., Berg, C. J., Yeargin-Allsopp, M. Boyle, C. A. \& Decoufle, P. Prenatal magnesium sulfate exposure and the risk for cerebral palsy or mental retardation among very low-birth-weight children aged 3 to 5 years. JAMA 276, 1805-1810 (1996).

241. Leviton, A. et al. Maternal receipt of magnesium sulfate does not seem to reduce the risk of neonatal white matter damage. Pediatrics 99, E2 (1997).

242. Paneth, N., Jetton, J., Pinto-Martin, J. \& Susser, M. Magnesium sulfate in labor and risk of neonatal brain lesions and cerebral palsy in low birth weight infants. The Neonatal Brain Hemorrhage Study Analysis Group. Pediatrics 99, E1 (1997).

243. Schlapbach L J et al. Impact of chorioamnionitis and preeclampsia on neurodevelopmental outcome in preterm infants below 32 weeks gestational age. Acta Paediatr. 99, 1504-1509 (2010).

244. Gray, P. H., Jones, P. \& O'Callaghan, M. J. Maternal antecedents for cerebral palsy in extremely preterm babies: a case-control study. Dev. Med. Child Neurol. 43, 580-585 (2001)

245. Murphy, D. J., Sellers, S., Mackenzie, I. Z., Yudkin, P. L $\&$ Johnson, A. M. Case-control study of antenatal and intrapartum risk factors for cerebral palsy in very preterm singleton babies. Lancet 346, 1449-1454 (1995).

246. Rouse, D. J. \& Hirtz, D. What we learned about the role of antenatal magnesium sulfate for the prevention of cerebral palsy. Semin. Perinatol. 40, 303-306 (2016).

247. Rouse, D. J. et al. A randomized, controlled trial of magnesium sulfate for the prevention of cerebral palsy. N. Engl. J. Med. 359, 895-905 (2008).

248. Zeng, X., Xue, Y. Tian, O., Sun, R. \& An, R. Effects and safety of magnesium sulfate on neuroprotection: a meta-analysis based on PRISMA Guidelines. Medicine 95, e2451 (2016)

249. Conde-Agudelo, A. \& Romero, R. Antenatal magnesium sulfate for the prevention of cerebral palsy in preterm infants less than 34 weeks' gestation a systematic review and metaanalysis. Am. J. Obstet. Gynecol. 200, 595-609 (2009).

250. Rouse, D. J. \& Gibbins, K. J. Magnesium sulfate for cerebral palsy prevention. Semin. Perinatol. 37 414-416 (2013).

251. Wolf, H. T., Hegaard, H. K., Greisen, G., Huusom, L. \& Hedegaard, M. Treatment with magnesium sulphate in pre-term birth: a systematic review and meta-analysis of observational studies. J. Obstetr. Gynaecol. 32, 135-140 (2012).

252. De Silva, D. A. et al. MAGnesium sulphate for fetal neuroprotection to prevent Cerebral Palsy (MAG-CP)implementation of a national guideline in Canada. Implement. Sci. 13, 8 (2018).

253. Turitz, A. L. Too, G. T \& Gyamfi-Bannerman, C. Proximity of magnesium exposure to delivery and neonatal outcomes. Am. J. Obstet. Gynecol. 215 508.e1-508.e6 (2016).

254. Ohhashi, M. et al. Magnesium sulphate and perinatal mortality and morbidity in very-low-birthweight infants born between 24 and 32 weeks of gestation in Japan. Eur. J. Obstet. Gynecol. Reprod. Biol. 201, 140-145 (2016).

255. McPherson, J. A., Rouse, D. J. Grobman, W. A Palatnik, A. \& Stamilio, D. M. Association of duration of neuroprotective magnesium sulfate infusion with neonatal and maternal outcomes. Obstet. Gynecol. 124, 749-755 (2014).

256. Gluckman, P. D. et al. Selective head cooling with mild systemic hypothermia after neonatal encephalopathy: multicentre randomised trial. Lancet 365, 663-670 (2005).

257. Vilchez, G., Dai, J., Lagos, M. \& Sokol, R. J. Maternal side effects and fetal neuroprotection according to body mass index after magnesium sulfate in a multicenter randomized controlled trial. J. Matern. Fetal Neonatal Med. 31, 178-183 (2018).

258. McAdams, R. M. \& Juul, S. E. Neonatal encephalopathy: update on therapeutic hypothermia and other novel therapeutics. Clin. Perinatol. 43, 485-500 (2016).

259. Jacobs, S. E. et al. Cooling for newborns with hypoxic ischaemic encephalopathy. Cochrane Database Syst. Rev. 1, CD003311 (2013). 
260. Leng, L. Hypothermia therapy after traumatic brain injury: a systematic review and meta-analysis. Turk. Neurosurg.https://doi.org/10.5137/1019-5149. JTN. 19696-16.2 (2017)

261. Chandrasekaran, M., Swamy, R., Ramji, S., Shankaran, S. $\&$ Thayyil, S. Therapeutic hypothermia for neonatal encephalopathy in Indian neonatal units: a survey of national practices. Indian Pediatr. 54, 969-970 (2017).

262. Thayyil, S. et al. Hypothermia for encephalopathy in low and middle-income countries (HELIX): study protocol for a randomised controlled trial. Trials 18 432 (2017).

263. Rao, R. et al. Safety and short-term outcomes of therapeutic hypothermia in preterm neonates 34-35 weeks gestational age with hypoxic-ischemic encephalopathy J Pediatr 183, 37-42 (2017).

264. Johnson, C. T., Burd, I., Raghunathan, R. Northington, F. J. \& Graham, E. M. Perinatal inflammation/infection and its association with correction of metabolic acidosis in hypoxic-ischemic encephalopathy. J. Perinatol 36 448-452 (2016).

265. Lee, J. K. et al. Optimizing cerebral autoregulation may decrease neonatal regional hypoxic-ischemic brain injury. Dev. Neurosci. 39, 248-256 (2017)

266. Landucci, E. et al. Neuroprotective effects of topiramate and memantine in combination with hypothermia in hypoxic-ischemic brain injury in vitro and in vivo. Neurosci. Lett. 668, 103-107 (2018).

267. Wu, Y. W. et al. Erythropoietin for neuroprotection in neonatal encephalopathy: safety and pharmacokinetics. Pediatrics 130, 683-691 (2012).

268. Clark, R. H., Bloom, B. T., Spitzer, A. R. \& Gerstmann, D. R. Reported medication use in the neonatal intensive care unit: data from a large national data set. Pediatrics 117, 1979-1987 (2006).

269. Schmidt, B. et al. Caffeine therapy for apnea of prematurity. N. Engl. J. Med. 354, 2112-2121 (2006).

270. Schmidt, B. et al. Survival without disability to age 5 years after neonatal caffeine therapy for apnea of prematurity. JAMA 307, 275-282 (2012)

271. Aly, H. et al. Melatonin use for neuroprotection in perinatal asphyxia: a randomized controlled pilot study. J. Perinatol 35, 186-191 (2015).

272. Wilkinson, D., Shepherd, E. \& Wallace, E. M. Melatonin for women in pregnancy for neuroprotection of the fetus. Cochrane Database Syst. Rev. 3 , CD010527 (2016)

273. Fischer, H. S., Reibel, N. J., Buhrer, C. \& Dame, C. Prophylactic early erythropoietin for neuroprotection in preterm infants: a meta-analysis. Pediatrics 139 (2017).

274. Kulak-Bejda, A., Kulak, P., Bejda, G., Krajewska-Kulak, E. $\&$ Kulak, W. Stem cells therapy in cerebral palsy: a systematic review. Brain Dev. 38, 699-705 (2016).

275. Kiasatdolatabadi, A. et al. The role of stem cells in the treatment of cerebral palsy: a review. Mol. Neurobiol. 54, 4963-4972 (2017)

276. Sun, J. M. et al. Effect of autologous cord blood infusion on motor function and brain connectivity in young children with cerebral palsy: a randomized, placebo-controlled trial. Stem Cells Trans/ Med. 6 2071-2078 (2017)

277. Solomons, G., Holden, R. H. \& Denhoff, E. The changing picture of cerebral dysfunction in early childhood. J. Pediatr. 63, 113-120 (1963).

278. Drillien, C. M. Abnormal neurologic signs in the first year of life in low-birthweight infants: possible prognostic significance. Dev. Med. Child Neurol. 14 575-584 (1972)

279. Nelson, K. B. \& Ellenberg, J. H. Children who “outgrew' cerebral palsy. Pediatrics 69, 529-536 (1982).

280. Taudorf, K., Hansen, F. J., Melchior, J. C. \& Pedersen, H. Spontaneous remission of cerebral palsy. Neuropediatrics 17, 19-22 (1986).

281. Pedersen, S. J., Sommerfelt, K. \& Markestad, T. Early motor development of premature infants with birthweight less than 2000 grams. Acta Paediatr. 89, 1456-1461 (2000)

282. Leach, E. L., Shevell, M., Bowden, K Stockler-Ipsiroglu, S. \& van Karnebeek, C. D. Treatable inborn errors of metabolism presenting as cerebral palsy mimics: systematic literature review. Orphanet J. Rare Dis. 9, 197 (2014).

283. Shevell, M. I., Majnemer, A., Poulin, C. \& Law, M. Stability of motor impairment in children with cerebral palsy. Dev. Med. Child Neurol. 50, 211-215 (2008).

284. Korzeniewski, S. J. et al. Persistence of cerebral palsy diagnosis: assessment of a low-birth-weight cohort at ages 2, 6, and 9 years. J. Child Neurol. 31, 461-467 (2016).

285. Zarrinkalam, R. et al. CP or not CP? A review of diagnoses in a cerebral palsy register. Pediatr. Neurol. 42, 177-180 (2010)

286. Novak, I. et al. Early, accurate diagnosis and early intervention in cerebral palsy: advances in diagnosis and treatment. JAMA Pediatr. 171, 897-907 (2017)

287. Spittle, A. J., Doyle, L. W. \& Boyd, R. N. A systematic review of the clinimetric properties of neuromotor assessments for preterm infants during the first year of life. Dev. Med. Child Neurol. 50, 254-266 (2008).

288. Bossuyt, P. M., Reitsma, J. B., Linnet, K. \& Moons, K. G Beyond diagnostic accuracy: the clinical utility of diagnostic tests. Clin. Chem. 58, 1636-1643 (2012).

289. Rosenbloom, L. What is the role of the General Movements Assessment in clinical practice? Dev. Med. Child Neurol. 60, 6 (2018).

290. Spittle, A., Orton, J., Anderson, P., Boyd, R. \& Doyle, L. W. Early developmental intervention programmes post-hospital discharge to prevent motor and cognitive impairments in preterm infants. Cochrane Database Syst. Rev. 12, Cd005495 (2012).

291. Morgan, C. et al. Effectiveness of motor interventions in infants with cerebral palsy: a systematic review. Dev. Med Child Neurol. 58, 900-909 (2016).

292. Korzeniewski, S. J., Birbeck, G., DeLano, M. C. Potchen, M. J. \& Paneth, N. A systematic review of neuroimaging for cerebral palsy. J. Child Neurol. 23 216-227 (2008)

293. Reid, S. M., Dagia, C. D., Ditchfield, M. R., Carlin, J. B. \& Reddihough, D. S. Population-based studies of brain imaging patterns in cerebral palsy. Dev. Med. Child Neurol. 56, 222-232 (2013).

294. White, T. et al. Paediatric population neuroimaging and the Generation R Study: the second wave. Eur. J. Epidemiol. 33, 99-125 (2017).

295. George, J. M. et al. Diagnostic accuracy of early magnetic resonance imaging to determine motor outcomes in infants born preterm: a systematic review and meta-analysis. Dev. Med. Child Neurol 60 134-146 (2018)

296. LeWinn, K. Z., Sheridan, M. A., Keyes, K. M., Hamilton, A. \& McLaughlin, K. A. Sample composition alters associations between age and brain structure. Nat. Commun. 8, 874 (2017).

297. Yanni, D. et al. Both antenatal and postnatal inflammation contribute information about the risk of brain damage in extremely preterm newborns. Pediatr. Res. 82, 691-696 (2017).

298. Korzeniewski, S. J. et al. Are preterm newborns who have relative hyperthyrotropinemia at increased risk of brain damage? J. Pediatr. Endocrinol. Metab. 27, 1077-1088 (2014)

299. Korzeniewski, S. J. et al. Elevated endogenous erythropoietin concentrations are associated with increased risk of brain damage in extremely preterm neonates. PLOS One 10, e0115083 (2015).

300. Leviton, A. et al. Two-hit model of brain damage in the very preterm newborn: small for gestational age and postnatal systemic inflammation. Pediatr. Res. 73. 362-370 (2013)

301. Barnett, M. L. et al. Exploring the multiple-hit hypothesis of preterm white matter damage using diffusion MRI. Neurolmage Clinical 17, 596-606 (2018).

302. Wixey, J. A., Chand, K. K., Colditz, P. B. \& Bjorkman, S. T. Review: Neuroinflammation in intrauterine growth restriction. Placenta 54, 117-124 (2017).

303. Korzeniewski, S. J. et al. A "multi-hit" model of neonatal white matter injury: cumulative contributions of chronic placental inflammation, acute fetal inflammation and postnatal inflammatory events. J. Perinat. Med. 42, 731-743 (2014)

304. Wang, L. W., Lin, Y. C., Wang, S. T., Yeh, T. F. \& Huang, C. C. Hypoxic/ischemic and infectious events have cumulative effects on the risk of cerebral palsy in very-low-birth-weight preterm infants. Neonatology 106, 209-215 (2014).

305. Schneider, R. E. et al. The association between maternal age and cerebral palsy risk factors. Pediatr. Neurol. 82, 25-28 (2018).

306. Last, J. A. Dictionary of Epidemiology 3rd edn (Oxford Univ. Press, 2002)

307. Phelps, W. M. The cerebral palsies. Clin. Orthopaed. Related Res. 44, 83-88 (1966).

308. Stanley, F. J. \& Watson, L. The cerebral palsies in Western Australia: trends, 1968 to 1981. Am. J. Obstet. Gynecol. 158, 89-93 (1988).

309. Blair, E., Badawi, N. \& Watson, L. Definition and classification of the cerebral palsies: the Australian view. Dev. Med. Child Neurol. Suppl. 109, 33-34 (2007).

310. Alberman, E. D. \& Stanley, F. J. The Epidemiology of the Cerebral Palsies (Blackwell Scientific Publications, 1984).

311. Yeargin-Allsopp, M. Distribution of motor types in cerebral palsy: how do registry data compare? Dev. Med. Child Neurol. 53, 199-200 (2011).

312. Nguyen, L., Mesterman, R. ¿ Gorter, J. W. Development of an inventory of goals using the International Classification of Functioning, Disability and Health in a population of non-ambulatory children and adolescents with cerebral palsy treated with botulinum toxin $A$ BMC Pediatr. 18, 1 (2018).

313. Bartlett, D., Dyszuk, E., Galuppi, B. \& Gorter, J. W. Interrelationships of functional status and health conditions in children with cerebral palsy: a descriptive study. Pediatr. Phys. Ther. 30, 10-16 (2018).

314. Paulson, A. \& Vargus-Adams, J. Overview of four functional classification systems commonly used in cerebral palsy. Children 4, E30 (2017).

315. Nelson, K. B. \& Ellenberg J. H. Obstetric complications as risk-factors for cerebral-palsy or seizure disorders. JAMA 251, 1843-1848 (1984)

316. Nelson, K. B. \& Ellenberg, J. H. Antecedents of cerebral palsy. I. Univariate analysis of risks. Am. J. Dis. Child 139, 1031-1038 (1985).

317. Tollanes, M. C. et al. Cohort profile: cerebral palsy in the Norwegian and Danish birth cohorts (MOBAND-CP). BMJ Open 6, e012777 (2016).

318. Myatt, L. et al. Strategy for standardization of preeclampsia research study design. Hypertension 63 1293-1301 (2014).

319. Hyams, K. C. Developing case definitions for symptom-based conditions: the problem of specificity. Epidemiol. Rev. 20, 148-156 (1998).

320. Weiss, N. S. \& Liff, J. M. Accounting for the multicausal nature of disease in the design and analysis of epidemiologic studies. Am. J. Epidemiol. 117, 14-18 (1983).

321. Schang, A. L., Gressens, P. \& Fleiss, B. Revisiting thyroid hormone treatment to prevent brain damage of prematurity. J. Neurosci. Res. 92, 1609-1610 (2014).

322. Dowding, V. M. \& Barry, C. Cerebral palsy: social class differences in prevalence in relation to birthweight and severity of disability. J. Epidemiol. Commun. Health 44, 191-195 (1990).

323. Ahlin, K. et al. Non-infectious risk factors for different types of cerebral palsy in term-born babies: a population-based, case-control study. BJOG 120 724-731 (2013)

324. Freire, G., Shevell, M. \& Oskoui, M. Cerebral palsy: phenotypes and risk factors in term singletons born small for gestational age. Eur. J. Paediatr. Neurol. 19 , 218-225 (2015)

325. Stanek, J. L., Emerson, J. A., Murdock, F. A \& Petroski, G. F. Growth characteristics in cerebral palsy subtypes: a comparative assessment. Dev. Med. Child Neurol. 58, 931-935 (2016).

326. Ahlin, K., Himmelmann, K., Nilsson, S., Sengpiel, V. \& Jacobsson, B. Antecedents of cerebral palsy according to severity of motor impairment. Acta Obstet. Gynecol. Scand. 95, 793-802 (2016).

327. Zelnik, N. et al. The role of prematurity in patients with hemiplegic cerebral palsy. J. Child Neurol. 31 , 678-682 (2016)

328. Kitai, Y. et al. Outcome of hemiplegic cerebral palsy born at term depends on its etiology. Brain Dev. 38 267-273 (2016)

329. Yang, Y. et al. Hypoxic stress forces adaptive and maladaptive placental stress responses in early pregnancy. Birth Defects Res. 109, 1330-1344 (2017).

330. Lahti-Pulkkinen, M. et al. Placental morphology is associated with maternal depressive symptoms during pregnancy and toddler psychiatric problems. Sci. Rep. 8, 791 (2018).

331. Labarrere, C. A. et al. Failure of physiologic transformation of spiral arteries, endothelial and trophoblast cell activation, and acute atherosis in the basal plate of the placenta. Am. J. Obstet. Gynecol. 216, 287 e1-287 e16 (2017).

332. Korzeniewski, S. J. et al. Maternal plasma angiogenic index-1 (placental growth factor/soluble vascular endothelial growth factor receptor-1) is a biomarker for the burden of placental lesions consistent with uteroplacental underperfusion: a longitudinal case-cohort study. Am. J. Obstet. Gynecol. 214 , 629.e1-629.e17 (2016).

333. McCowan, L. M. et al. Prediction of small for gestational age infants in healthy nulliparous women 
using clinical and ultrasound risk factors combined with early pregnancy biomarkers. PLOS One 12 e0169311 (2017)

334. Kumar, M. et al. Adverse fetal outcome: is first trimester ultrasound and Doppler better predictor than biomarkers? J. Matern. Fetal Neonatal Med. 30 1410-1416 (2017).

335. Levine, R. J. et al. Circulating angiogenic factors and the risk of preeclampsia. N. Engl. J. Med. 350, 672-683 (2004)

336. O'Gorman, N. et al. Accuracy of competing-risks model in screening for pre-eclampsia by maternal factors and biomarkers at 11-13 weeks' gestation. Ultrasound Obstet. Gynecol. 49, 751-755 (2017).

337. Bolnick, J. M. et al. Altered biomarkers in trophoblast cells obtained noninvasively prior to clinical manifestation of perinatal disease. Sci. Rep. 6, 32382 (2016).

338. Moser, G., Drewlo, S., Huppertz, B. \& Armant, D. R. Trophoblast retrieval and isolation from the cervix: origins of cervical trophoblasts and their potential value for risk assessment of ongoing pregnancies. Hum. Reprod. Update. https://doi.org/10.1093/ humupd/dmy008 (2018)

339. Joyner, M. J. \& Pedersen, B. K. Ten questions about systems biology. J. Physiol. 589, 1017-1030 (2011).

340. Kotas, M. E. \& Medzhitov, R. Homeostasis, inflammation, and disease susceptibility. Cell 160 816-827 (2015)

341. Lisovska, N. et al. Pathogenesis of cerebral palsy through the prism of immune regulation of nervous tissue homeostasis: literature review. Childs Nerv. Syst. 32, 2111-2117 (2016)

342. Chovatiya, R. \& Medzhitov, R. Stress, inflammation, and defense of homeostasis. Mol. Cell 54, 281-288 (2014).
343. Hagberg, H., Gressens, P. \& Mallard, C. Inflammation during fetal and neonatal life: implications for neurologic and neuropsychiatric disease in children and adults. Ann. Neurol. 71, 444-457 (2012).

344. Fleiss, B. $\&$ Gressens, P. Tertiary mechanisms of brain damage: a new hope for treatment of cerebral palsy? Lancet Neurol. 11, 556-566 (2012).

345. Reuss, M. L., Paneth, N. \& Susser, M. Does the loss of placental hormones contribute to neurodevelopmental disabilities in preterm infants? Dev. Med. Child Neurol. 36, 743-747 (1994)

346. Schang A. L. et al. Failure of thyroid hormone treatment to prevent inflammation-induced white matter injury in the immature brain. Brain Behav. Immun. 37, 95-102 (2014).

347. Stroustrup, A., Teitelbaum, S. L. \& Aschner, J. L. The value of preterm infant environmental health cohorts: the canary in the coal mine. JAMA Pediatr. 171 1139-1140 (2017)

348. Myatt, L. \& Roberts, J. M. Preeclampsia: syndrome or disease? Curr. Hypertension Rep. 17, 83 (2015).

349. Goldenberg, R. L. et al. The preterm birth syndrome: issues to consider in creating a classification system. Am. J. Obstet. Gynecol. 206, 113-118 (2012).

350. Catov, J. M. et al. Neonatal outcomes following preterm birth classified according to placental features. Am. J. Obstet. Gynecol. 216, 411.e1-411. e14 (2017).

351. Park, E. Y. $\&$ Kim, W. H. Prevalence of secondary impairments of adults with cerebral palsy according to gross motor function classification system. J. Phys. Ther. Sci. 29, 266-269 (2017).

352. Kovo, M. et al. Pregnancy outcome and placental findings in pregnancies complicated by fetal growth restriction with and without preeclampsia. Reprod. Sci. 22, 316-321 (2015).
353. Roberts, J. M., Redman, C. W. G. \& Global Pregnancy, C. Global Pregnancy, C. Global Pregnancy Collaboration symposium: Prepregnancy and very early pregnancy antecedents of adverse pregnancy outcomes: overview and recommendations. Placenta 60, 103-109 (2017).

354. Roberts, J. M., Mascalzoni, D., Ness, R. B., Poston, L. $\&$ Global Pregnancy Collaboration. Collaboration to understand complex diseases: preeclampsia and adverse pregnancy outcomes. Hypertension 67 , 681-687 (2016)

355. Paneth, N \& Monk, C. The importance of cohort research starting early in life to understanding child health. Curr. Opin. Pediatr. 30, 292-296 (2018).

\section{Author contributions}

All authors researched data for the article, wrote the article and reviewed and/or edited the manuscript before submission. S.J.K. and N.P. made substantial contributions to discussion of the content for the article.

\section{Competing interests}

The authors declare no competing interests.

\section{Publisher's note}

Springer Nature remains neutral with regard to jurisdictional claims made in published maps and institutional affiliations.

\section{Reviewer information}

Nature Reviews Neurology thanks R. Boyd, D. Damiano and K. Graham for their contribution to the peer review of this work.

RELATED LINKS

CoLab: https://pregnancycolab.tghn.org/ 